\title{
Adolescent Girls Empowerment Programme: Research and evaluation baseline technical report
}

\author{
Paul C. Hewett \\ Population Council \\ Karen Austrian \\ Population Council \\ Erica Soler-Hampejsek \\ Population Council \\ Jere R. Behrman \\ Christine A. Kelly \\ Population Council
}

See next page for additional authors

Follow this and additional works at: https://knowledgecommons.popcouncil.org/departments_sbsr-pgy

Part of the Demography, Population, and Ecology Commons, Family, Life Course, and Society

Commons, International Public Health Commons, and the Women's Health Commons

How does access to this work benefit you? Let us know!

\section{Recommended Citation}

Hewett, Paul C., Karen Austrian, Erica Soler-Hampejsek, Jere R. Behrman, Christine A. Kelly, Dela KusiAppouh, Fiammetta Bozzani, Barbara Mensch, and Minyoi Maimbolwa. 2014. "Adolescent Girls Empowerment Programme: Research and evaluation baseline technical report." Lusaka: Population Council. 


\section{Authors}

Paul C. Hewett, Karen Austrian, Erica Soler-Hampejsek, Jere R. Behrman, Christine A. Kelly, Dela KusiAppouh, Fiammetta Bozzani, Barbara Mensch, and Minyoi Maimbolwa 


\section{ADOLESCENT GIRLS} EMPOWERMENT PROGRAMME

\section{RESEARCH AND EVALUATION}

\section{BASELINE TECHNICAL REPORT}

APRIL 2014

Corresponding Authors

Paul C. Hewett, PhD

AGEP Research Lead Investigator

Senior Associate

Population Council, Zambia

Plot 3670, No. 4

Mwaleshi Road, Olympia Park

Lusaka, Zambia

+260211295925

phewett@popcouncil.org

Karen Austrian, PhD

AGEP Principal Investigator

Associate

Population Council, Kenya

General Accident House - 2nd Floor

Ralph Bunche Road

PO Box 17643-00500

Nairobi, Kenya

Tel: +254-20-2713480

Fax: +254-20-2713479

kaustrian@popcouncil.org

\section{Contributing Authors}

\section{Elloa Soler-Hampejsek, PhD}

Associate

Population Council, New York

Jere R. Behrman, PhD

Professor of Economics

University of Pennsylvania

Christine A. Kelly, MSe

Research Associate

Population Council, New York

Dela Kusi-Appouh, PhD

Post-Doctoral Fellow

Population Council, Zambia

Flametta Borannl, PhD

Research Fellow

LSHTM, London

Barbara S. Mensch, PhD

Senior Associate

Population Council, New York

Minyol Malmbolwa, Bse

Data Manager

Population Council, Zambia

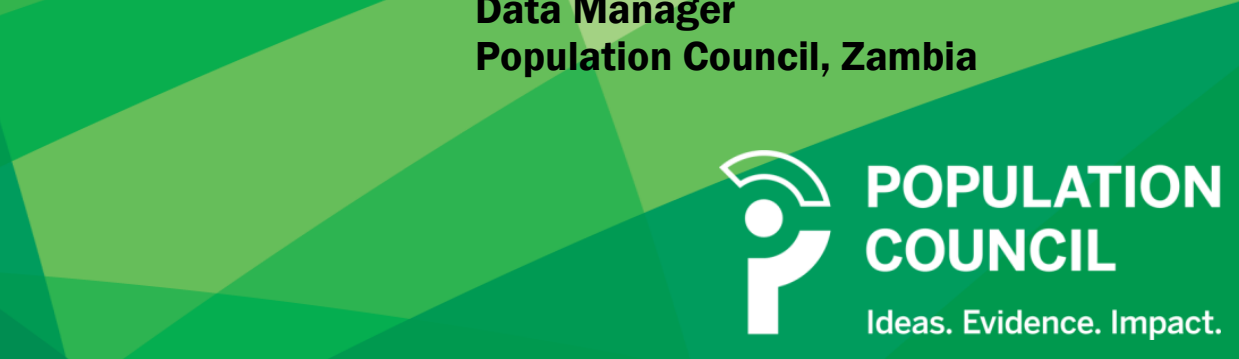


The Population Council confronts critical health and development issues-from stopping the spread of HIV to improving reproductive health and ensuring that young people lead full and productive lives. Through biomedical, social science, and public health research in 50 countries, we work with our partners to deliver solutions that lead to more effective policies, programmes, and technologies that improve lives around the world. Established in 1952 and headquartered in New York, the Council is a nongovernmental, nonprofit organization governed by an international board of trustees.

\section{Population Council, Zambia}

Plot 3670, No. 4

Mwaleshi Road, Olympia Park

Lusaka, Zambia

Tel: $\quad+260211295925$

email: info.zambia@popcouncil.org

Suggested citation: Hewett, Paul C., Karen Austrian, Erica Soler-Hampejsek, Jere R. Behrman, Christine A. Kelly, Dela Kusi-Appouh, Fiammetta Bozzani, Barbara S. Mensch, and Minyoi Maimbolwa. 2014. Adolescent Girls Empowerment Programme: Research and Evaluation Baseline Technical Report. Lusaka, Zambia. Population Council. 


\section{Table of Contents}

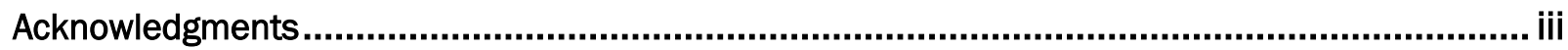

List of Abbreviations......................................................................................................... iv

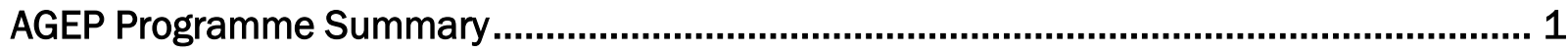

Three Core Components of AGEP in Zambia ................................................................ 1

AGEP Population.......................................................................................................... 2

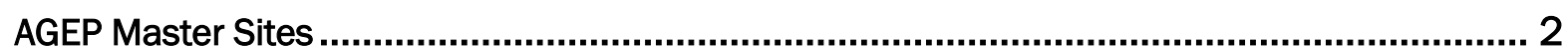

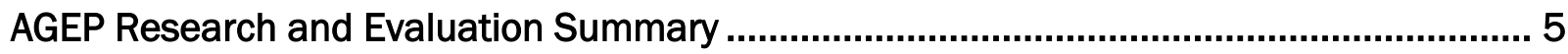

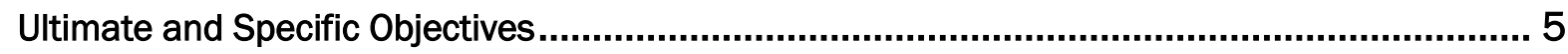

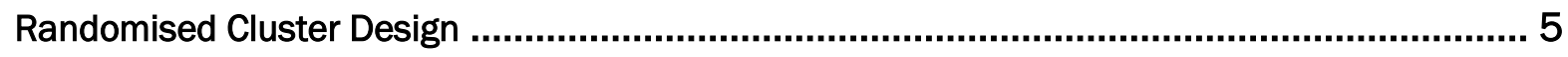

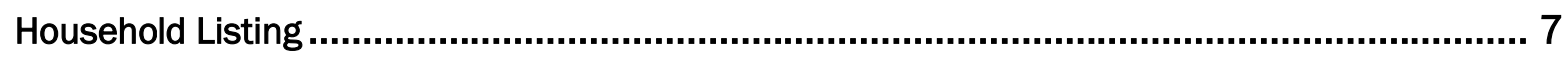

Adolescent Quantitative Survey .................................................................................. 7

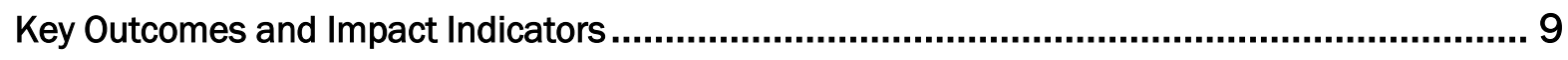

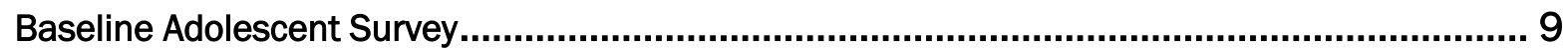

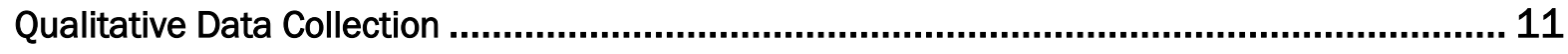

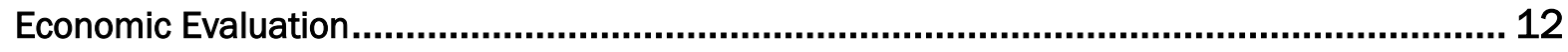

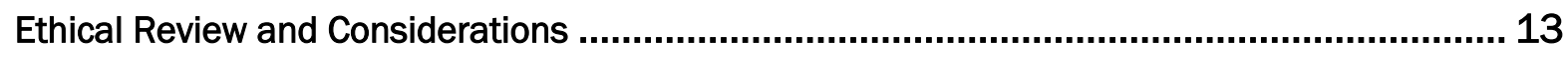

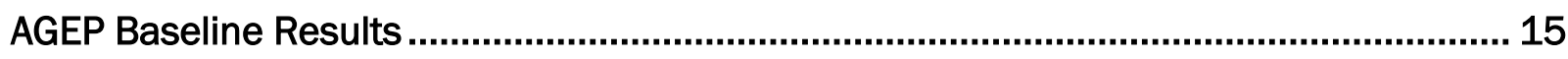

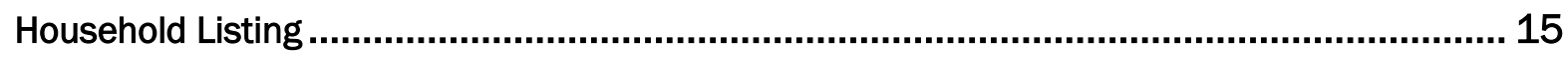

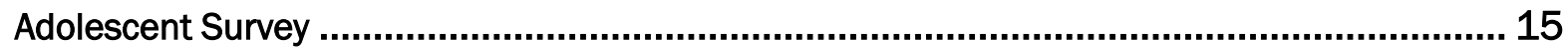

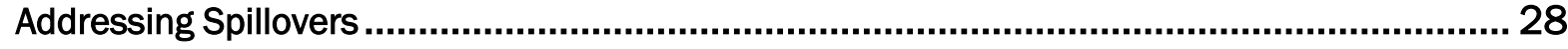

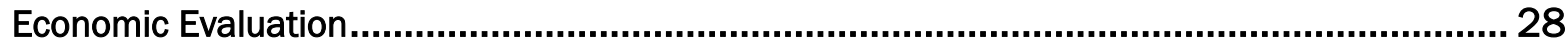

Baseline Challenges and Lessons Learned ................................................................... 30

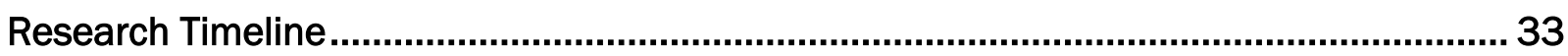




\section{Acknowledgments}

This baseline technical report would not be possible without the hard work of diverse programme and research teams dedicated to improving the lives of vulnerable adolescent girls.

At the Population Council: Natalie Jackson Hachonda and her team of programme officers and site coordinators, worked to prepare the communities for AGEP and the research component and are implementing an expansive and complex intervention. We thank Kevin Kapungu and Mary Namukoko who served as study coordinators, Dominic Nzala and Paul Banda who supervised the household listing in the field, Oscar Mbulwe who supervised the biomarker collection component of the survey, Rogers Musonda who served as the study cartographer, Memoona Malik who supervised the anthropometric measurement, all the team of team leaders and research assistants who spent so many days in the field collecting data. We would also like to acknowledge the efforts of the finance and administrative team at Population Council Zambia, including Masida Chisambi, Swedish Sianyaka, Khukhie Makukisi and Memory Sichizuwe. Additional thanks to Samir Souidi and Stan Mierzwa at the Population Council headquarters for the development of the tablet based electronic data capture tools.

At the YWCA Zambia, we would like to acknowledge the efforts of Bernard Munkombwe and Debbie Chingobe Kangombe who were also instrumental in the preparation and implementation of research and programme activities at field level.

We also thank the Ministry of Health and the Ministry of Community Development Mother and Child Health for their support of AGEP overall, and the research specifically. Special thanks to Dr. Maximillian Bweupe, Dr. Elizabeth Chizema and Dr. Peter Mwape at the Ministry of Health and Dr. Carol Phiri, Dr. Mary Nambao, Dr. Mwiche and Mr. Kakusa at the Ministry of Community Development Mother and Child Health.

The authors thank the UK Department for International Development (DFID) and those from DFID who provided feedback on the Inception report. DFID's investment in rigorous research will benefit not only Zambia, but the field of adolescent girls programming as a whole.

Finally, we are grateful to the adolescent girls who shared their thoughts and experiences with us and thank them for participating in both the programme and the research. 


\section{List of Abbreviations}

ACAS

Audio Computer-Assisted Self-Interviewing

AGEP

Adolescent Girls Empowerment Programme

CAPI

Computer-Assisted Personal-Interviewing

CSA Census Supervisory Area

CSO Central Statistical Office

DCHO District Community Health Office

DHS

Demographic and Health Survey

$\mathrm{HC}$

Health Centre

HSV-2

Herpes Simplex Virus - type 2

IDI

In-Depth Interviews

$\mathrm{MCDMCH} \quad$ Ministry of Community Development, Mother and Child Health

$\mathrm{MOH}$

Ministry of Health

NatSave

National Savings and Credit Bank

OLS

Ordinary Least Squares

$\mathrm{RCD}$

Randomised Cluster Design

RED

Research Evidence Division

$\mathrm{RHC}$

Rural Health Centre

SEA

Standard Enumeration Area

UNZA-BREC

University of Zambia, Biomedical Research Ethics Committee

YWCA Young Women's Christian Association 


\section{AGEP Programme Summary}

The theory of change behind AGEP posits that adolescent girls are empowered (the desired outcome) by acquiring social, health and economic assets, that they can then draw on to reduce vulnerabilities and expand opportunities, thereby increasing their likelihood of completing school and delaying sexual debut, and reducing the risk of early marriage, unintended pregnancy, acquisition of HIV, and so on (the impact). A more detailed description of the AGEP programme can be found in the AGEP Pilot Report. ${ }^{1}$

\section{Three Core Components of AGEP in Zambia}

Safe Spaces: Implemented in partnership with YWCA Zambia, safe spaces are weekly girls' group meetings in which 20 to 30 girls get together with a mentor-a young woman from their community-for short training sessions on a variety of topics as well as an opportunity to discuss their experiences in the past week. AGEP has developed three curricula used in the context of these meetings: 1) a health and life skills curriculum, 2) a financial education curriculum, and 3) a nutrition curriculum for adolescent girls. Each trained mentor uses the same curricula and is instructed on the order in which the sessions should be delivered to ensure standardization across all groups.

Savings accounts: The Population Council has worked in partnership with the National Savings and Credit Bank (NatSave) and Making Cents International to develop the "Girls Dream" Savings Account for AGEP girls. The NatSave account has a very low minimum opening balance of KW 2.5 (US \$0.50) and any amount can be deposited or withdrawn with no fee. Mentors in the savings arm are trained by AGEP staff in the savings account features and in turn the mentors conduct an orientation session with the girls and their co-signatory prior to account opening, to instruct them how to use the account and begin the account opening process. A field trip to the branch is also organized for girls and their co-signatory to complete the account opening process. Currently, there are approximately 32 NatSave branches throughout Zambia.

Health vouchers: In partnership with the Ministry of Community Development, Mother and Child Health (MCDMCH), participants receive a health voucher that is redeemable for a package of health services at partner public and private healthcare providers. The services covered by the voucher include basic wellness exams as well as age-appropriate sexual and reproductive health services. During the weekly meetings, mentors teach the girls in the group about the voucher services and inform them of the participating clinics where the voucher can be used. For private and NGO providers, payment is made on a "fee for service" basis with pre-approved reimbursement rates, whereas for the public facilities an incentive for each service is paid to the District Community Health Office (DCHO) and then distributed between the district health office and the clinic in previously agreed-upon percentages.

\footnotetext{
${ }^{1}$ Available at http://www.popcouncil.org/uploads/pdfs/2013PGY_AGEP-PilotReport.pdf.
} 
AGEP serves vulnerable adolescent girls in Zambia aged 10 to 19 in two age cohorts: 10-14 year-olds and 15-19 year-olds. AGEP groups are also stratified by marital/fertility status; separate safe spaces groups exist for married adolescents and young mothers. AGEP is designed to reach a minimum of 11,200 girls by the end of the programme, 1,200 in the pilot and 10,000 in the scaled-up programme. All AGEP participants are drawn from lower-income backgrounds and live with multiple levels of vulnerability, e.g., physical and social isolation, living without parents, living in low-income households, and not attending school. In service to the AGEP goal of reaching the most vulnerable girls and the necessity of conducting a randomised evaluation, information was collected through a household survey subsequently used as a sampling frame to determine eligible girls for participation in the programme. This method of invitation contrasts with community recruitment and self-selection processes used by many other programmes, which make very difficult identifying intervention effects from selection into the programme.

\section{AGEP Master Sites}

AGEP operates in ten "master-sites," five urban and five rural, in four provinces of Zambia. Study provinces and the number of sites per province were selected purposefully, on the basis of feasibility of operating the AGEP programme while also conducting a research evaluation, as well as through discussions with the donor regarding the type of target populations. A "master-site" in a rural area contains multiple contiguous or proximal villages or chiefdoms, while in urban sites the programme is implemented within high-density housing compounds. The programme communities in urban areas are directly proximal to participating banks and health centres; in rural areas there are on average greater distances between households and health facilities and participating banks.

To select sites within the study provinces, a site sampling frame containing two or three public health facilities proximal to each other was generated. Urban and rural areas were treated separately. For urban master sites, adjacent high-density compounds that included the necessary two or more health facilities were considered a single unit for sampling. This was done to achieve a sufficient number of randomisation units (clusters) for the second stage of selection. A sampling frame of high-density compounds was generated for Lusaka and, separately, for Kabwe, Ndola and Kitwe. A total of seven such possible master sites were identified in Lusaka, and an additional five possible master sites were identified in Kabwe, Ndola and Kitwe. ${ }^{2}$ Two urban sites were randomly selected from the Lusaka sampling frame, and three urban sites were randomly selected from Kabwe, Ndola and Kitwe. The selected urban master sites are listed in Table 1 below.

\footnotetext{
${ }^{2}$ One high-density compound in Lusaka was considered too dangerous to operate AGEP and conduct the research study and was therefore not included in the sampling frame. Another possible Lusaka site was removed from the sampling frame because it had too few CSAs to randomise and was adjacent to higher-income residential areas.
} 
Table 1. Selected Urban Master Sites

\begin{tabular}{|c|c|c|c|c|}
\hline Site \# & Site Name & Province & District & Study Health Facilities \\
\hline 1 & Chawama \& Misisi & Lusaka & Lusaka & Chawama HC, Kamwala HC \\
\hline 2 & Chipata \& Chazanga & Lusaka & Lusaka & Chipata HC, Chazanga HC \\
\hline 3 & Kabwe & Central & Kabwe & $\begin{array}{l}\text { Makululu HC, Katondo HC, Mahatma } \\
\text { Ghandi Memorial HC }\end{array}$ \\
\hline 4 & Ndola & Copperbelt & Ndola & $\begin{array}{l}\text { Twapia HC, Mushili HC, Kaloko HC, } \\
\text { Chipulukusu Clinic }\end{array}$ \\
\hline 5 & Kitwe & Copperbelt & Kitwe & $\begin{array}{l}\text { Kawama HC, Kwacha HC, Bulangililo HC, } \\
\text { Ipuskilo HC }\end{array}$ \\
\hline
\end{tabular}

$\overline{\mathrm{HC}}=$ Health Centre

In rural areas, separate site-level sampling frames were created for Central, Copperbelt and North-Western Provinces. Criteria for rural areas included a unit of randomisation (cluster) that fell within a 15 kilometre radius of a health clinic and within a 65-kilometre radius of a participating banking facility. Additionally, a sufficient number of clusters had to exist from which to randomise. In each of Central and Copperbelt provinces, a total of six possible master sites were identified and two randomly selected. Due to the low population density and large geographic size of clusters in North-Western Province, only one potential master site that fit the selection criteria was identified and selected. The selected rural master sites are listed in Table 2 below.

Table 2. Selected Rural Master Sites

\begin{tabular}{|c|c|c|c|c|}
\hline Site \# & Site Name & Province & District & Health Facilities \\
\hline 6 & Mumbwa & Central & Mumbwa/Shibuyunji ${ }^{3}$ & $\begin{array}{l}\text { Miyooye RHC, Lwili RHC, Chiwena RHC } \\
\text { Kapyanga RHC }\end{array}$ \\
\hline 7 & Kapiri Mposhi & Central & Kapiri Mposhi & $\begin{array}{l}\text { Mulungushi RHC, Luanshimba RHC, } \\
\text { Kakulu RHC, Chibwe RHC }\end{array}$ \\
\hline 8 & Masaiti B & Copperbelt & $\begin{array}{l}\text { Luanshya, Masaiti, } \\
\text { Mpongwe }\end{array}$ & $\begin{array}{l}\text { Masaiti Boma RHC, Masaiti Council } \\
\text { RHC, Chinondo RHC, }\end{array}$ \\
\hline 9 & Masaiti A & Copperbelt & Masaiti & $\begin{array}{l}\text { Kambowa RHC, Chondwe RHC, } \\
\text { Mutaba RHC, Njelemani RHC }\end{array}$ \\
\hline 10 & North-Western & North-Western & Solwezi & $\begin{array}{l}\text { Kapijimpanga RHC, Luamala RHC, } \\
\text { Mitukutuku RHC, Kamisenga RHC }\end{array}$ \\
\hline
\end{tabular}

$\overline{\mathrm{RHC}}=$ Rural Health Centre

\footnotetext{
${ }^{3}$ After site selection, a new district was created that included one of the previously selected RHCs.
} 
Figure 1 shows the distribution of master sites across Zambia. Red circles indicate urban sites: two in Lusaka, one in Kabwe in Central Province, one in Kitwe and one in Ndola, both in Copperbelt Province. Green circles indicate rural sites: two in Mumbwa and Kapiri Mposhi in Central Province, two Masaiti-area sites in Copperbelt Province and one in Solwezi, NorthWestern province. ${ }^{4}$

Figure 1. Geographic location and site number of AGEP urban and rural master sites

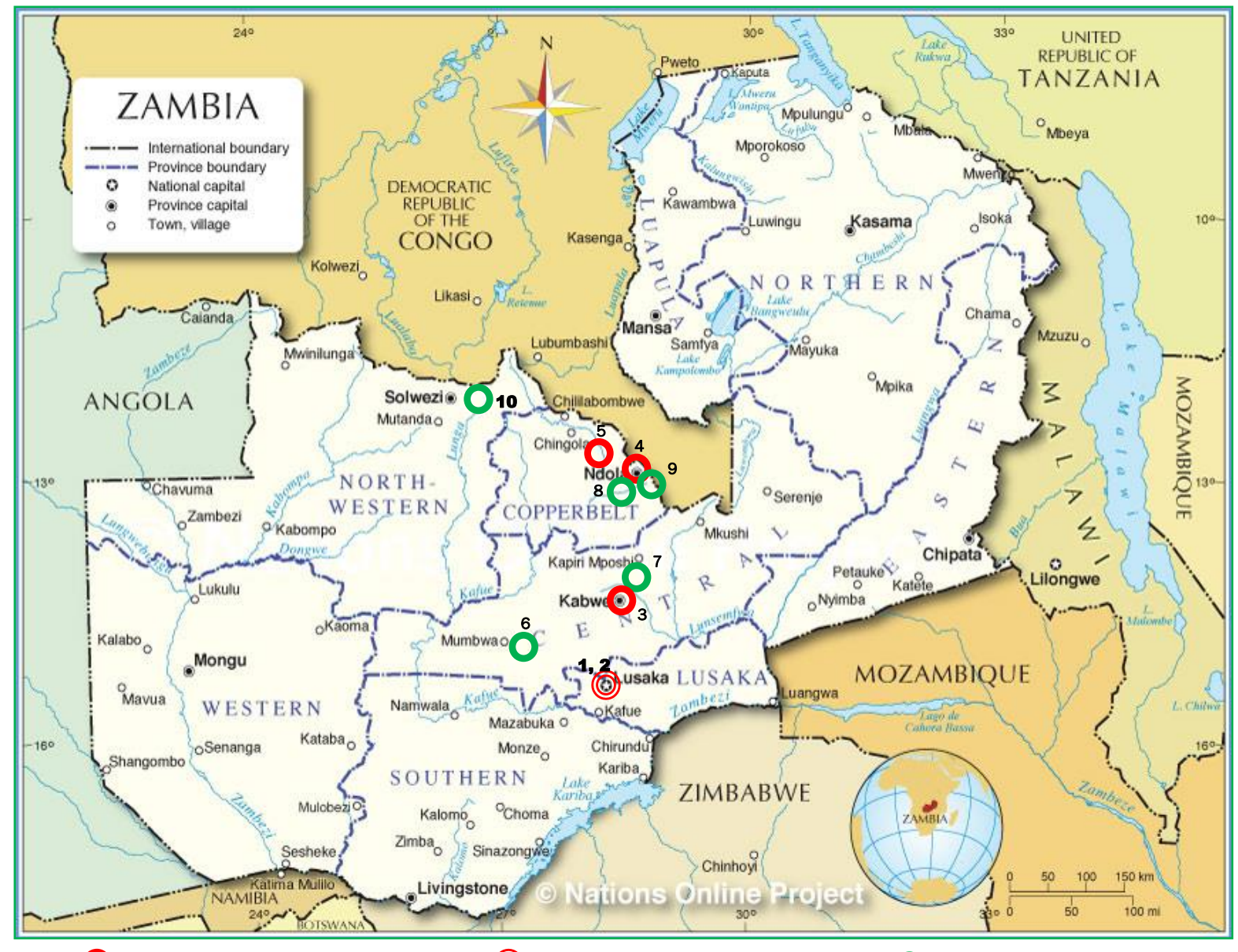

One urban site

(2) Two urban sites

One rural site

\footnotetext{
${ }^{4}$ Recently, Northern Province was split into two separate provinces, Northern and Machinga. This is not indicated on the map.
} 


\section{AGEP Research and Evaluation Summary}

The design of the AGEP research and evaluation component was developed after numerous discussions and working sessions with study investigators, the Evidence Scrutiny Committee (ESC) and the UK Department for International Development (DFID). Subsequent, feedback on the AGEP research design that led to further refinement was provided by programme and independent evaluators, including DFID - Research Evidence Division (RED), HLSP consultants, and the World Bank.

\section{Ultimate and Specific Objectives}

The primary aim of this research is to obtain as rigorous an assessment as possible of the impact of AGEP on mediating as well as longer-term demographic, reproductive, and health outcomes among vulnerable adolescent girls as they age from 10 to 19 years old in 2013 to ages 14 to 23 in 2017. The specific objectives are to assess for vulnerable adolescent girls:

- the impact of the full AGEP package on longer-term demographic, reproductive, and health outcomes

- how the full AGEP package affects mediating outcome indicators

- the marginal impact of individual components of AGEP on longer-term indicators

- the marginal impact of individual components of AGEP on mediating outcome indicators

- how the full AGEP package affects mediating outcome indicators and how these, in turn, affect longer-term impact indicators

- the marginal impact of individual components of AGEP on mediating outcome indicators and how these, in turn, affect longer-term impact indicators

\section{Randomised Cluster Design}

To rigorously evaluate the impact of the AGEP and its core components, it was determined that due to the design of AGEP and the need to evaluate its individual components a randomised cluster design (RCD) was required. Selected clusters in the master sites were randomised to receive different combinations of AGEP components. The experimental and control arms of the study are displayed in Table 3 along with their associated components. All girls selected for participation in AGEP within the cluster receive the intervention that has been randomly selected for that cluster; girls in clusters for the control arm receive neither intervention nor placebo exposures.

Table 3. Randomisation arms of AGEP

\begin{tabular}{l|l}
\hline Arm & AGEP Components \\
\hline Experimental 1 & Safe Spaces Only \\
\hline Experimental 2 & Safe Spaces + Health Voucher \\
Experimental 3 & Safe Spaces + Health Voucher + Savings Accounts \\
\hline Control & No Programme \\
\hline
\end{tabular}


A cluster is defined as a Census Supervisory Area (CSA) as delineated by the Zambia Central Statistical Office (CSO). A CSA contains a collection of adjacent standard enumeration areas (SEA) that range in number from two to eight per CSA. SEAs are a convenient geographical area that contains approximately 100 households in rural areas and 150 households in urban areas. Accordingly, with on average about five SEAs, CSAs contain approximately 750 households in urban areas. In rural areas, with on average three SEAs, there are approximately 300 households per CSA. As the CSAs and SEAs are not updated regularly by the CSO, the average number of households can vary considerably in individual SEAs and CSAs. CSAs in urban areas are relatively small geographic areas, perhaps a few hundred metres long and wide, while in rural areas they can be much larger, encompassing numerous square kilometres.

The number of clusters and adolescent girls needed for the research component was determined by estimating minimally detectable effect sizes for a representative set of impact indicators given a statistical power (.80), alpha (.05), intra-class correlation, and effect size determination. ${ }^{5}$ Optimal Design Software for clustered randomised trials was used to obtain sample size estimates. Results of the sample size calculations indicate that 40 clusters study per arm are required with a minimum of 20 girls per cluster by the end of the evaluation. The four-arm study design dictates that AGEP operate in 120 communities, conducting research in 40 additional control communities. Each master site, therefore, has 12 experimental and 4 control CSAs that were randomly selected. The total number of clusters available for randomisation ranged from 24 to 48 in the five master urban sites and from 20 to 32 in the five master rural sites.

Once the CSAs were delineated for each AGEP site, the selection of CSAs for the programme and control arms was conducted through random assignment at a public lottery. The public lottery was conducted to maximize the transparency and community acceptance of AGEP component assignments. Local political and community leaders were invited to participate in the lottery, conducted at a centrally located public facility. The lottery was conducted via a twostep selection process in which a CSA was randomly selected for participation and then an AGEP arm randomly assigned. The designated arm of the study was then pinned on a large display map of the master site to show where the programme component would be located. This process was repeated until all 16 clusters were determined. One public lottery was conducted in each AGEP master site.

Given the geographic proximity of experimental and control arms in urban areas and the potential for spillover effects from AGEP to control areas, an additional four CSAs were selected and designated as "external" controls for each of the five urban master sites. The selection of each external control site was based on a nearest, non-adjacent neighbour rule. The rationale for this rule was, as much as was possible, to maximize the socioeconomic, demographic, community and geographic similarities of the AGEP master and external control sites, while also building in physical separation to minimize spillover effects from the programme. A total of four CSAs were selected for each external site using a matching procedure based on the number of households in the CSA. For each site, the selected 16

\footnotetext{
${ }^{5}$ The impact indicators are listed in Table 4 below.
} 
AGEP research CSAs were ordered and divided into quartiles based on household size. The average size of the quartile was then matched with a similar cluster based on household size in the external control site.

\section{Household Listing}

A mapping and survey all households in SEAs within randomly selected CSAs was conducted, and a total of approximately 81,000 households listed. The definition of a household was based on the Demographic and Health Surveys (DHS), including that the members have the same household head and share the same pot or kitchen. A household instrument was completed by the head of the household or, if he/she was not available, the spouse of the head of the household or, if spouse not available, another adult household member. The household instrument included a complete roster of all household members, and questions about the household member's age, schooling, parents' survivorship, marital status, number of living children, and disability status. The instrument also included questions about the quality of the house, asset ownership, the number of deaths in the household in the previous year, household savings and travel time to schools, health centres, banks and markets.

Given the magnitude of the effort required to list households in all CSAs and SEAs needed for the AGEP programme and research, a filtering question at the beginning of the household interview determined whether the interviewer was to complete the full household roster. The filtering question was, "How many adolescent girls 8-21 years of age live in this household?" Two additional years were included on either end of the age bracket to minimize intentional age misreporting and heaping. The filtering question was embedded within a series of five questions about the household to reduce the possibility that households might learn through word of mouth that an effort was underway to specifically identify adolescent girls.

\section{Adolescent Quantitative Survey}

Selection of girls: The adolescent girls who were to participate in AGEP were selected from the household listing. A vulnerability indicator was constructed (discussed below) and girls were ranked by their vulnerability score. Those with the highest levels of vulnerability in each master site were selected for the programme. Girls who were residing in boarding schools or were mentally disabled were excluded, while all girls with physical disabilities were automatically invited. A total of 16,649 adolescent girls within the 10 master sites were invited to participate in AGEP. The selection of these girls was done in three steps: (1) 13,751 girls were selected based on their vulnerability score; (2) 340 additional girls were selected in select clusters to achieve a minimum of 30 girls per age group per CSA; and, (3) 2,558 girls living in the same households as the girls selected in the previous steps were also invited to participate. 
The following criteria were used for recruiting the selected adolescent girls into the AGEP research component at baseline:

- Selected for AGEP in step 1 above (experimental areas only) ${ }^{6}$

- Between the ages of 10-19 years

- Never married

- Socioeconomic vulnerability

- Residence in selected CSAs in AGEP programme or control areas

- Capable of meeting the obligations of the research

Measuring vulnerability: All AGEP participants are girls from lower income backgrounds and living with multiple levels of socioeconomic vulnerabilities that include, but are not limited to, physical and social isolation, living without parents, living in low-income households, and not attending school. One important consideration in identifying vulnerable girls for participation is not to over-represent girls who have already manifested their vulnerability in terms of the outcomes to be measured, e.g., by dropping out of school, becoming pregnant, or getting married. This consideration is important from both programmatic and research perspectives as these outcomes are the programme's impact indicators. It is, therefore, preferable to attempt to capture girls who are vulnerable and at the cusp of manifesting adverse adolescent life course outcomes.

The method used to identify vulnerable adolescent girls was to select those behind school grade for age as a proxy for vulnerability. Early in the school-going process, many children fall behind in school due to late entry, repetition of grades, and temporary withdrawal from school; all are the result of some degree of personal and household vulnerability. An ordinary least squares (OLS) regression was estimated with the number of grades behind for age; regressors included age, not in school, ever married and number of living children. The estimated residual of the OLS was then used to represent vulnerability, with higher residuals indicating higher vulnerability. Adolescent girls were ordered by the estimated levels of vulnerability and selected according to the number required for the sample at each master site.

Research sample sizes: The sample size calculations indicated that 3,600 unmarried girls in the research component would be needed at endline to assess all key study impact indicators. This number included 3,200 girls in the AGEP masters sites (160 clusters $x 20$ girls per cluster), distributed by arm, and 400 girls in the external control areas ( 20 clusters $\times 20$ girls per cluster). To determine the number of girls required at baseline, estimates were needed of non-response at baseline (20\% for ages 10-14, 35\% for ages 15-19), refusals for biological specimen collection (15\%), and attrition over time (an additional $20 \%$ per year). Non-response at baseline included such factors as the household or adolescent not being located, refusals of parents or adolescents, and incapacitation and death. In addition, an estimate of HIV and HSV-2 testing refusal (15\%) was considered for those aged 15-19 among whom testing was being conducted. Accounting for these factors an estimated sample of 7,200 adolescent girls (3,060 aged 10-14, 4,140 aged 15-19) was to be sampled for the baseline interview,

\footnotetext{
${ }^{6}$ One girl per household was randomly selected for the research component.
} 
specifically 4,800 in AGEP programme components, 1,600 in the internal control clusters and 800 in the external control areas.

\section{Key Outcomes and Impact Indicators}

Although a wide range of outcome and impact indicators will be measured throughout the study period, a smaller set served as key indicators for measuring programme impact. These indicators were used for estimating cluster number and sample size requirements For AGEP girls, exposure to the programme is expected to result in an increase in a comprehensive set of social, human and financial assets that allow them to gain control of their health and economic decisions. In turn, these assets should serve to improve their life trajectories by increasing their educational attainment, delaying sexual debut, reducing unwanted pregnancy and STIs, increasing their ability to support themselves and their families financially, and increasing their control over health and financial decision making. These outcomes are hypothesized to ultimately reduce poverty for participants and their future families and communities. A representative set of output, mediating, and longer-term indicators is listed in Table 4.

Table 4. Outcome and impact indicators

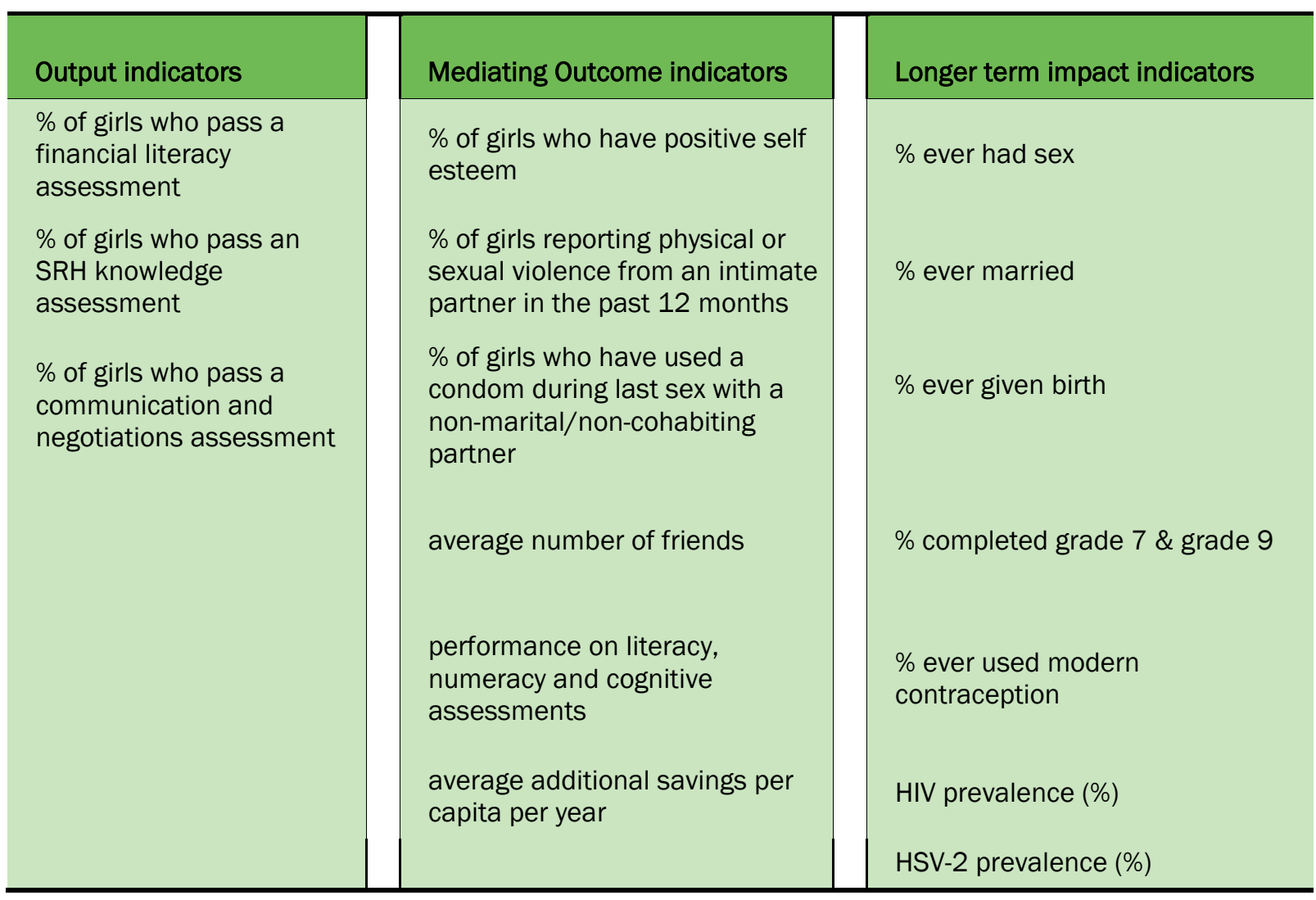

\section{Baseline Adolescent Survey}

The adolescent survey instruments are intended to measure changes in attitudes, behaviours, transition status, social assets and cognitive skills that may occur over time related to: 1) schooling attainment and transitions; 2) sexual activity, relationship status and sexual partners; 3) marriage and marital dissolution; 4) sexual and physical coercion and violence; 5) gender attitudes, self-efficacy and locus of control; 6) labour force participation and savings 
behaviour; 7) living arrangements and household resources; 8) mobility and migration; 9) literacy, numeracy and cognitive skills and ability; 10) financial literacy and knowledge. The information collected from adolescents is useful for assessing the potential differential impact of the AGEP programme by subgroups, as well as for increasing the power of the statistical assessment of the programme's impact by taking into account these measured covariates.

Table 5. Summary of study instruments and measures

\begin{tabular}{|c|c|c|}
\hline Instrument & Key elements & Ages \\
\hline \multirow[t]{2}{*}{$\begin{array}{l}\text { Younger } \\
\text { Adolescent } \\
\text { Survey }\end{array}$} & $\begin{array}{l}\text { Household sociodemographic characteristics } \\
\text { Schooling history } \\
\text { Social assets and networks } \\
\text { Self-efficacy and locus-of-control } \\
\text { Financial literacy, savings behaviour and livelihood activities } \\
\text { Self-reported health, reproductive health knowledge, and nutrition }\end{array}$ & $10-14$ \\
\hline & Experience of physical harassment and violence & $13-14$ \\
\hline $\begin{array}{l}\text { Older } \\
\text { Adolescent } \\
\text { Survey }\end{array}$ & $\begin{array}{l}\text { Household sociodemographic characteristics } \\
\text { Schooling history } \\
\text { Social assets and networks } \\
\text { Self-efficacy and locus-of-control } \\
\text { Financial literacy, savings behaviour and livelihood activities } \\
\text { Relationship history and marriage } \\
\text { Sexual and reproductive behaviour } \\
\text { Experience of physical harassment and violence } \\
\text { Self-reported health, reproductive health knowledge, and nutrition } \\
\text { HIV and AIDS risk perception } \\
\text { Utilization of antenatal and postnatal care services }\end{array}$ & $15-19$ \\
\hline $\begin{array}{l}\text { Adolescent } \\
\text { Literacy, Math, } \\
\text { Cognitive Skills }\end{array}$ & $\begin{array}{l}\text { Reading ability and comprehension in local language and English Excerpts } \\
\text { from official mathematics assessments multiple grades Ravens } \\
\text { Progressive Matrices cognitive testing }\end{array}$ & $10-19$ \\
\hline
\end{tabular}

The questionnaires were translated into the most common local languages spoken in the selected provinces. Surveys were implemented, where feasible, by electronic data capture using Samsung Galaxy tablets. Computer-Assisted Personal-Interviewing (CAPI) was used for questions that were non-sensitive. CAPI is a process of data capture in which the interviewer reads the question from a computer screen and enters the participant's response directly into a handheld or tablet device. For sensitive questions, Audio Computer-Assisted SelfInterviewing (ACASI) was used. With ACASI the respondent listens on headphones to prerecorded questions and response categories while (if desired and if the participant is literate) simultaneously reading the question on the tablet screen. The participant enters a response by touching a colour coded number or option as specified in the audio script and on the tablet screen. ACASI maximizes confidentiality and privacy of response, since no one can hear or see the question being read, nor the response option selected.

Anthropometric data: To capture the shorter- and longer-term impact of nutrition on health outcomes, anthropometric data, specifically the participant's height and weight, were collected. The capture of height and weight allows for the measurement of key indices to assess nutritional status, including body-mass index, height-for-age, weight-for-height, and weight-for-age. Anthropometric data were also collected from the living children aged five and 
younger of study participants to assess the impact of nutrition during pregnancy and postpartum on child growth. The equipment selected for and the procedures for implementing the anthropometric measurement were drawn from the Demographic and Health Surveys.

Biological markers were collected from adolescents aged 15-19 at baseline. The HIV and HSV-2 specimens were collected at the household or in a private space in the community in cases where confidential interviewing and testing could not be done at home. HIV testing and counseling followed national guidelines and was conducted by certified staff. HIV rapid tests were used and results provided directly to the adolescent at the time of specimen collection. If the adolescent was uncomfortable receiving her results at the household she was able to obtain them at the local health clinic. The HSV-2 biological specimens were collected via finger prick. A sample of whole blood was collected, stored in microtainers and laboratory tested using the Kalon ELISA antibody test. The HSV-2 test results and associated counseling were provided to the participant at the local health clinic. A voucher with an anonymous identification number was provided to the adolescent to collect her results and procedures were established that were to be followed if the participant lost or did not have her voucher.

\section{Qualitative Data Collection}

The AGEP research study also collected qualitative data-in the form of in-depth interviews (IDIs)-among a subset of girls participating in all four AGEP arms. Quantitative methods alone would limit measurement of the extent to which adolescent girls can feel empowered by the social, health, and economic assets offered by AGEP. Collecting qualitative data can shed light on how adolescents perceive and understand the actions they can (or cannot) take to engender positive outcomes in their lives. IDIs offer a unique opportunity to speak to girls on a one-on-one basis and gain a deeper appreciation of their subjective experience and interpretation of phenomena affecting their daily lives. The IDIs also may result in modifications or additions that improve subsequent rounds of quantitative data collection. Data derived from these in-depth conversations benefit both the programme and research sides of AGEP.

IDI instrument design: The in-depth interview guide uses open-ended question to examine a number topics corresponding to key AGEP outcomes and indicators. The open-ended format allows for flexibility to adapt the questions and topics to the flow of the interview and, in some cases, explore beyond questions originally asked. The broad topic areas covered in the guide are as follows:

- Socio-demographic characteristics: age, number of siblings and birth order

- AGEP experience: lessons learned, usefulness, improvement

- AGEP attendance: frequency, limitations, improvement

- Life goals, social support, agency: school completion, marriage, number of children, work/occupation, social network, intimate relationships, sexual relationships

- Locus of control: chance happenings; habit of planning; sources of influence on health, finances, marriage, children, aspirations

- Health self-efficacy: confidence in seeking health services; experience seeking health services

- Financial self-efficacy: confidence in and practice of money management 
The interview guide questions are tailored to girls' marital status, childbearing status, age group, and programme arm. Sexual and reproductive health-related questions are omitted for 10-14 year-olds.

To link qualitative data to quantitative data, girls eligible for an IDI were selected from the survey sample. Even though the aim of collecting qualitative data is not to have a representative sample, girls were purposively selected based on criteria combining programme and research strengths: programme arm, age group, vulnerability level, total number of meetings attended, and population density.

IDls are being conducted in four of the ten master sites that reflect the diversity of catchment sites across provinces, and include two in large urban areas of Lusaka and Ndola, and two rural sites in Mumbwa and Solwezi. A total of 192 girls are interviewed at baseline, midline, and endline; translating to 48 girls (36 AGEP, 12 control) per site. The geographic dispersion of these sites also encompasses differences in predominant languages, namely Nyanja and Bemba in Lusaka; Bemba in Ndola; Lenje, Nyanja, and Bemba in Mumbwa; and Kaonde in Solwezi. IDIs are conducted in the relevant local languages by trained interviewers and then transcribed into English.

Baseline qualitative data have been collected in Lusaka (November/December 2013) and Ndola (February 2014), collection is underway in Mumbwa (March/April 2014), to be followed by Solwezi (May 2014). Data are being analysed using ATLAS.ti qualitative analysis software. The analysis involves multiple readings of the transcripts by a team of at least two analysts coding in a systematic manner and identifying themes and sub-themes. The findings of the baseline qualitative data collection will be available in the second half of 2014 .

\section{Economic Evaluation}

An economic evaluation of AGEP will be undertaken alongside the randomised research and evaluation with the following objectives:

1. To present programme costs by expenditure category from the point of view of all service providers, including the Population Council, health facilities, and the National Savings and Credit Bank

2. To estimate average costs per participant of the different experimental models

3. To calculate the difference in programme costs per participant by study arm

4. To undertake standard statistical analysis on participant-specific out-of-pocket cost estimates

5. To estimate incremental costs per negative health outcome averted and positive progress achieved on selected output and impact indicators by study arm

6. To compare the incremental costs of programme implementation between urban and rural sites

The cost-effectiveness study consists of four main components: (1) collation of programme resource-use utilization data from the Population Council and implementation partners; (2) collection of participant-specific out-of-pocket and indirect costs data; (3) micro-costing exercise at two health facilities to estimate the costs of health services offered through the 
voucher scheme; and (4) decision-analytic modeling for combining programme cost and effect data to generate incremental cost-effectiveness ratios.

Decision-analytic modeling: To combine the cost and effect data into a common analysis, a decision-analytic model will be constructed to generate estimates of the incremental costs per negative health outcome averted and positive progress achieved on non-health indicators from participating in AGEP. Non-health output measures, comparing the AGEP cohort to the control cohort and to the corresponding age group in the whole country, will include the incremental costs for every additional programme participant reporting a positive achievement on each of the indicators illustrated in Table 4. Health-related output measures will include the incremental cost per disability-adjusted life year (DALY) averted due to HIV and HSV-2 infection under each experimental model.

The relative cost-effectiveness of the different models will be analysed by calculating and comparing incremental cost-effectiveness ratios. Probabilistic sensitivity analysis will be conducted by assigning probability distributions to cost and effect parameters and running a Monte Carlo simulation 10,000 times.

All of the data collected during the baseline phase will be input into the final model, which will be developed over the course of 2015 and populated during the last year of programme evaluation. In addition to the costing analysis conducted on each individual outcome, an index will be created that will rank the outcomes in terms of their impact on the girls' lives. The purpose of the index will be to enhance the interpretation of cost-effectiveness results from each arm of AGEP by adding a layer of qualitative information on how the participants themselves value the programme outcomes. Because each outcome might not have the same 'importance' (e.g. educational attainment vs. HIV infection), each outcome will be given a weight, which will in turn determine its ranking within the composite score. Each arm of AGEP will then be assigned a "cost-effectiveness score" based on its performance on the set of outcomes and its costs. As weighting is a subjective process, the Council will integrate a series of questions into the second round of qualitative data collection (to be collected in the second half of 2015), that will allow AGEP participants themselves to rank the importance of the different outcomes. Those data, in addition to evidence from the literature on the various outcomes, will be used to weight the individual outcomes accordingly, which will then be used to build a composite score.

\section{Ethical Review and Considerations}

The research protocol was approved by the Population Council Institutional Review Board (PCIRB) and the University of Zambia's Biomedical Research Ethics Committee (UNZA-BREC). After obtaining ethical clearances, the protocol was also reviewed by the Zambian Ministry of Health $(\mathrm{MOH})$. The Population Council's IRB has a Department of Health and Human Services (DHHS) federal wide assurance number of FWA00000279, and has established procedures that adhere to the U.S. Federal guidelines for human subjects as set forth in Title 45, Part 46 of the Code of Federal Regulations (Department of Health and Human Services 1991). UNZA BREC's federal wide assurance number is FWA00000338. 
Written informed consent was obtained from adults participating in the household listing or adolescent survey prior to participation. For research activities involving minors (aged 10-17), written informed consent of the parent/legal guardian was sought, followed by the written agreement (assent) of the youth. Separate informed consent was obtained from participants aged 15-19 before collecting biological specimens. All participants were asked to provide consent to be contacted again in future survey rounds. Research activities were informed by Ethical Approaches to Gathering Information from Children and Adolescents in International Settings: Guidelines and Resources (Schenk and Williamson 2005). 


\section{AGEP Baseline Results}

\section{Household Listing}

The household listing was conducted between late April and October 2013 prior to the initiation of the adolescent survey in each master site. A total of 81,068 structures were visited; of these, $7 \%$ were not households or were vacant. From the remaining 75,086 households, $85 \%$ participated in the household listing exercise, $14 \%$ had no adult member available to complete the interview after a maximum of three attempts to visit the household, and $1 \%$ refused participation. A total of 39,605 girls in the age range 10 to 19 , living in $42 \%$ of households that completed the interview, were listed. Girls reported as attending boarding school (552 girls) and girls reported as having a mental disability (162 girls) were not eligible for participation in the AGEP programme or research. This left 38,891 eligible girls aged 1019 , from 26,277 households.

\section{Adolescent Survey}

Fieldwork for the adolescent survey was initiated in July 2013 and completed in February 2014. The fieldwork team consisted of 30 study enumerators who were trained and certified in HIV testing and counseling, a cartographer, a data manager, a biomarker coordinator, three drivers and a fieldwork project coordinator. In addition, an unpaid project intern pursuing a Masters in Public Health provided field monitoring and quality assurance support.

As discussed above, the target research sample to be visited for the baseline adolescent survey was 7,200 girls aged 10-19, consisting of 3,060 aged 10-14 years and 4,140 aged 15-19 years. These numbers included girls in the intervention and internal and external controls. The actual research sample that could be visited in the master sites was 6,893 girls aged 10-19: 3,002 aged 10-14 and 3,891 aged 15-19. The lower number of actual girls to be visited relative to the target was due to the fact that girls were ranked by their vulnerabity determined at the site level and in some CSAs there were not enough girls who met the vulnerability criteria to reach the maximum desired target number of girls for AGEP and research. Further, only one girl per household was randomly selected to participate in the research, limiting the total number of available girls.

Table 6 presents the total number of girls aged 10-19 years identified in the household listing, the number of girls in the sampling frame driven by the selection criteria and the actual target research sample by study master sites. As can be observed, the percentage of the total number of girls aged 10-19 years who were selected for AGEP in both intervention and control arms varies considerable by urban (38\%) and rural (85\%) areas. The research sample represents approximately $14 \%$ of girls aged $10-19$ years in urban areas and $27 \%$ of girls in rural areas. 
Table 6. Household listing sampling frame and target research sample of adolescent girls, by study site

\begin{tabular}{|c|c|c|c|c|c|c|}
\hline & \multicolumn{3}{|c|}{ Household Listing } & \multicolumn{3}{|c|}{ Target research samplea } \\
\hline & $\begin{array}{c}\text { Total Girls } \\
\text { 10-19 } \\
\text { (a) }\end{array}$ & $\begin{array}{l}\text { Sampling } \\
\text { frame }^{b} \\
\text { (b) }\end{array}$ & $\begin{array}{c}\% \\
\text { (b)/(a) }\end{array}$ & $10-14$ & $15-19$ & Total \\
\hline \multicolumn{7}{|l|}{ Study Site } \\
\hline Urbanc & 27,777 & 10,491 & 37.8 & 1,656 & 2,204 & 3,860 \\
\hline Site \#1 - Lusaka: C. \& M. & 4,927 & 2,109 & 42.8 & 340 & 447 & 787 \\
\hline Site \#2 - Lusaka: C. \& C. & 6,082 & 2,046 & 33.6 & 326 & 440 & 766 \\
\hline Site \#3 - Kabwe & 4,112 & 2,068 & 50.3 & 333 & 460 & 793 \\
\hline Site \#4 - Ndola & 6,762 & 2,164 & 32.0 & 328 & 435 & 763 \\
\hline Site \#5 - Kitwe & 5,894 & 2,104 & 35.7 & 329 & 422 & 751 \\
\hline Rural & 11,114 & 9,487 & 85.4 & 1,346 & 1,687 & 3,033 \\
\hline Site \#6 - Mumbwa & 2,582 & 2,019 & 78.2 & 266 & 339 & 605 \\
\hline Site \#7 - Kapiri Mposhi & 1,432 & 1,432 & 100.0 & 272 & 317 & 589 \\
\hline Site \#8 - Masaiti B & 2,260 & 2,015 & 89.2 & 272 & 355 & 627 \\
\hline Site \#9 - Masaiti A & 2,039 & 2,010 & 98.6 & 272 & 345 & 617 \\
\hline Site \#10 - North-Western & 2,801 & 2,011 & 71.8 & 264 & 331 & 595 \\
\hline Total & 38,891 & 19,978 & 51.4 & 3,002 & 3,891 & 6,893 \\
\hline
\end{tabular}

a Criteria: 1) must be selected for AGEP in intervention arm, 2) only one randomly selected adolescent per household

b In urban sites: 1,200 were selected for three AGEP intervention arms, 400 for internal controls, 400 external controls. In rural sites: 1,500 were select for AGEP and 500 for internal controls. Numbers vary by site due to a limit on the total number of girls available or ties in vunerability residual.

c Includes external controls CSAs

Table 7 indicates the distribution of the target research sample of adolescent girls by study arm, age group and urban and rural residence. As can be discerned from the table, the distribution of adolescent girls that were to be interviewed in each arm of the study is relatively equal, ranging from 1,526 to 1,563 girls. The number of adolescent girls to be interviewed by arm and master site vary due to the fact that, as mentioned above, in some CSAs there were not enough girls living in different households who were selected for AGEP to reach the estimated number of girls for the research. The table also indicates a target urban sample of 3,860 and a rural sample of 3,033 , differing largely due to the inclusion of the adolescent girls sampled from the external control clusters. 
Table 7. Target research sample of adolescent girls by study arm

\begin{tabular}{|c|c|c|c|c|c|}
\hline & & es from & ehold $\mathrm{Li}$ & & \\
\hline & & & & & \\
\hline & Urban & Rural & Urban & Rural & Total \\
\hline Study Arms & & & & & \\
\hline SS & 340 & 334 & 457 & 413 & 1,544 \\
\hline $\mathrm{SS}+\mathrm{HV}$ & 338 & 340 & 454 & 431 & 1,563 \\
\hline $\mathrm{SS}+\mathrm{HV}+\mathrm{SA}$ & 329 & 332 & 439 & 426 & 1,526 \\
\hline Control Internal & 329 & 340 & 443 & 417 & 1,529 \\
\hline Control External & 320 & -- & 411 & -- & 731 \\
\hline Total & 1,656 & 1,346 & 2,204 & 1,687 & 6,893 \\
\hline
\end{tabular}

Response Rates: There were a range of factors that influenced whether a participant's baseline data was obtained, including survey non-response and a determination of noneligibility at the time of the interview. The categories of non-response and non-eligibility for the baseline survey are displayed in Table 8.

Table 8. Baseline interview results and response rates

\begin{tabular}{|c|c|c|c|c|c|c|}
\hline & \multicolumn{4}{|c|}{ Household Listing Ages } & & \\
\hline & \multicolumn{2}{|c|}{$10-14$} & \multicolumn{2}{|c|}{$15-19$} & \multicolumn{2}{|c|}{ Total } \\
\hline & Urban & Rural & Urban & Rural & $\mathrm{N}$ & $\%$ \\
\hline Sample Target & 1,656 & 1,346 & 2,204 & 1,687 & 6,893 & 100 \\
\hline Eligible & 1,504 & 1,219 & 1,893 & 1,349 & 5,965 & 100 \\
\hline Completed & 1,366 & 1,114 & 1,601 & 1,161 & 5,242 & 87.9 \\
\hline Refusals & 28 & 14 & 66 & 31 & 139 & 2.3 \\
\hline Incapacitated/Died & 5 & 1 & 18 & 6 & 30 & 0.5 \\
\hline Not located / not available & 99 & 87 & 196 & 146 & 528 & 8.9 \\
\hline Missing electronic data & 6 & 3 & 12 & 5 & 26 & 0.4 \\
\hline Not Eligible & 152 & 127 & 311 & 338 & 928 & 100 \\
\hline Age out-of-range & 52 & 45 & 46 & 44 & 187 & 20.2 \\
\hline Males & 5 & 10 & 16 & 9 & 40 & 4.3 \\
\hline Ever married & 6 & 3 & 124 & 164 & 297 & 32.0 \\
\hline Relocated/Living elsewherea & 84 & 65 & 116 & 117 & 382 & 41.2 \\
\hline \multirow[t]{2}{*}{ Duplicates } & 5 & 4 & 9 & 4 & 22 & 2.4 \\
\hline & \multicolumn{2}{|c|}{$10-14$} & \multicolumn{2}{|c|}{$15-19$} & \multicolumn{2}{|c|}{ Total } \\
\hline Response rate of eligible \% & \multirow{2}{*}{\multicolumn{2}{|c|}{$\begin{array}{l}91.1 \\
82.6\end{array}$}} & \multirow{2}{*}{\multicolumn{2}{|c|}{$\begin{array}{l}85.2 \\
71.0\end{array}$}} & \multicolumn{2}{|c|}{87.9} \\
\hline Response rate of total \% & & & & & & \\
\hline
\end{tabular}

a Including girls residing in boarding school.

Of the 6,839 adolescent girls targeted for interview at baseline, 5,242 completed the baseline survey. This represents a response rate of $88 \%$ among those adolescents who met the eligibility criteria of the research. Reasons for non-response include refusals from the parents/guardians or adolescents $(2 \%)$, incapacitation or death $(<1 \%)$ the inability to locate the household or adolescent for the interview (9\%) and a marginal number of cases in which the survey was indicated as completed but the electronic data were not obtained $(<.5 \%)$. 
A sizable number of cases, 928 in total, represent adolescents who, despite appearing to satisfy the research requirements in the household listing, were determined to be ineligible for the research at the time of the interview, including those whose age was out-of-range (20\%), were males (4\%), ever married (32\%), relocated or living elsewhere (41\%) or were duplicate entries (2\%). These cases are often due to misreporting by the household head or adult at the household interview or by incorrect entry of data by the household listing staff. Some of these cases, however, are the results of a change in the adolescent's marital status or residential location in the gap between the household listing and adolescent survey. Accounting for both non-response and non-eligibility, approximately $76 \%$ of the baseline target sample completed the survey. These response rates are higher than the minimal estimates needed for the baseline interviews used in generating the adolescent sample.

Table 9 presents the response rates for the anthropometric measurement and the biological specimen collection at the baseline interview, by age and residential location.

Table 9. Anthropometry and biomarkers response rates at baseline

\begin{tabular}{|c|c|c|c|c|c|c|}
\hline & \multicolumn{4}{|c|}{ Survey Ages } & & \\
\hline & \multicolumn{2}{|c|}{$10-14$} & \multicolumn{2}{|c|}{$15-19$} & \multicolumn{2}{|c|}{ Total } \\
\hline & Urban & Rural & Urban & Rural & $\mathbf{N}$ & $\%$ \\
\hline Completed baseline survey & 1,495 & 1,219 & 1,472 & 1,056 & 5,242 & 100 \\
\hline Difference from $\mathrm{HH}$ listing ages ${ }^{a}$ & 129 & 105 & -129 & -105 & & \\
\hline \multicolumn{7}{|l|}{ Response rate, \% } \\
\hline Completed Anthropometry & 99.9 & 100 & 99.4 & 99.8 & 5,242 & 99.8 \\
\hline Completed HIV & - & - & 94.4 & 97.5 & 2,528 & 95.7 \\
\hline Completed HSV-2 & -- & -- & 94.0 & 97.0 & 2,528 & 95.2 \\
\hline
\end{tabular}

a Due to misreporting of ages during the baseline survey and the time between the household listing and the baseline survey, the girls' ages reported at the time of the interview were not always the same as those reported in the household listing. Hence, the distribution of ages is different by age group from that in Table 8 above.

Response rates for the anthropometry component were very high: anthropometric data was obtained from $99.8 \%$ of the 5,242 girls who completed the baseline survey. Response rates for the biological specimen collection were also high. Of the 2,528 girls ages 15-19 who completed the baseline survey, 95.7\% were tested for HIV and 95.2\% provided the biological specimen for HSV-2. The response rates for HIV and HSV-2 testing are approximately $10 \%$ higher than those estimated in generating the baseline sample sizes needed to evaluate these outcomes.

Sample non-response and balance: An important consideration in sampling by experimental arm is to assure that there is balance across the experimental and control clusters with regard to the observed and unobserved characteristics of the population. This issue was examined in two ways, first by assessing whether baseline non-response differed by study arm and, secondly, by the distribution of key sociodemographic characteristics. 
Table 10. Comparison of response rates across study arms

\begin{tabular}{|c|c|c|c|c|c|}
\hline & \multicolumn{4}{|c|}{ Household Listing Ages } & \multirow[b]{3}{*}{ Total } \\
\hline & \multicolumn{2}{|c|}{$10-14$} & \multicolumn{2}{|c|}{$15-19$} & \\
\hline & Urban & Rural & Urban & Rural & \\
\hline & \multicolumn{4}{|c|}{ Response rate of those eligible } & \\
\hline \multicolumn{6}{|l|}{ Study Arms } \\
\hline AGEPa & 90.4 & 92.6 & 85.0 & 86.7 & 88.4 \\
\hline Control Internal & 90.1 & 88.1 & 84.4 & 84.1 & 86.4 \\
\hline \multirow[t]{2}{*}{ Control External } & 92.9 & -- & 83.4 & -- & 87.6 \\
\hline & \multicolumn{4}{|c|}{ Response rate of total household sample } & \\
\hline \multicolumn{6}{|l|}{ Study Arms } \\
\hline AGEPa & 82.2 & 82.9 & 72.7 & 69.0 & 76.0 \\
\hline Control Internal & 80.5 & 82.4 & 71.8 & 68.3 & 75.1 \\
\hline Control External & 85.3 & -- & 73.2 & - & 78.5 \\
\hline
\end{tabular}

Table 10 compares the response rates by intervention (AGEP) and control areas (internal and external). A reasonable concern is that individuals in areas that are receiving the AGEP intervention will be more willing to participate in the research component than individuals in the control areas because they have a greater vested interest in AGEP. This issue is particularly salient for external control communities that receive neither the intervention nor any community level sensitization to AGEP. As can be discerned from the Total column in the Table 10, the response rates among those eligible reveal only marginally different participation rates, with the external controls response rates on par or higher than the AGEP or internal control areas.

There are other interesting observations about the response rates. As expected, the nonresponse among adolescents $15-19$ is higher than among 10-14 year-olds. This result is due to the greater mobility of older adolescents and the greater likelihood of working outside of the household. However, despite the apparent availability of increased economic options outside the household in urban areas, the response rates are similar across the urban and rural sample for both age groups. The lower response rates among the total household sample (lower panel of table) among 15-19 year-olds stem from the fact that a significant number of these girls were reported as married at time of the baseline interview, with a slightly higher rate in rural areas.

Another important issue regarding sample balance is whether the randomisation was successful such that the characteristics of the population are similar across the study arms. Table 11 compares a select number of baseline sociodemographic and behavioural characteristics as well as HIV status by control and programme arm. 
Table 11. Comparison of sociodemographic and behavioural characteristics, by study arm; \% (95\% confidence interval)

\begin{tabular}{|c|c|c|c|c|c|c|}
\hline \multirow[b]{2}{*}{ Indicator } & \multicolumn{2}{|c|}{ Rural } & \multicolumn{3}{|c|}{ Urban } & \multirow[b]{2}{*}{$\begin{array}{c}(6) \\
\text { Statistically } \\
\text { significant } \\
\text { differences } \\
(p<.05)\end{array}$} \\
\hline & $\begin{array}{c}(1) \\
\text { Programme } \\
\text { arms } \\
(\mathrm{N}=1710)\end{array}$ & $\begin{array}{c}(2) \\
\text { Internal } \\
\text { controls } \\
(\mathrm{N}=565)\end{array}$ & $\begin{array}{c}(3) \\
\text { Programme } \\
\text { arms } \\
(\mathrm{N}=1810)\end{array}$ & $\begin{array}{c}(4) \\
\text { Internal } \\
\text { controls } \\
(\mathrm{N}=583)\end{array}$ & $\begin{array}{c}(5) \\
\text { External } \\
\text { controls } \\
(\mathrm{N}=574)\end{array}$ & \\
\hline \multicolumn{7}{|l|}{ Respondent level } \\
\hline Age (mean) & $\begin{array}{c}14.2 \\
(14.0-14.3)\end{array}$ & $\begin{array}{c}14.1 \\
(13.9-14.4)\end{array}$ & $\begin{array}{c}14.3 \\
(14.2-14.5)\end{array}$ & $\begin{array}{c}14.4 \\
(14.2-14.6)\end{array}$ & $\begin{array}{c}14.3 \\
(14.1-14.6)\end{array}$ & \\
\hline Ever attended school & $\begin{array}{c}98.3 \\
(97.7-98.9)\end{array}$ & $\begin{array}{c}97.7 \\
(96.5-98.9)\end{array}$ & $\begin{array}{c}97.1 \\
(96.3-97.8)\end{array}$ & $\begin{array}{c}96.6 \\
(95.1-98.0)\end{array}$ & $\begin{array}{c}95.1 \\
(93.3-96.9)\end{array}$ & C \\
\hline $\begin{array}{l}\text { Highest grade } \\
\text { attended (mean)a }\end{array}$ & $\begin{array}{c}5.7 \\
(5.6-5.8)\end{array}$ & $\begin{array}{c}5.8 \\
(5.6-6.0)\end{array}$ & $\begin{array}{c}5.3 \\
(5.2-5.4)\end{array}$ & $\begin{array}{c}5.5 \\
(5.3-5.7)\end{array}$ & $\begin{array}{c}5.5 \\
(5.2-5.7)\end{array}$ & \\
\hline $\begin{array}{l}\text { Currently attending } \\
\text { school }\end{array}$ & $\begin{array}{c}82.6 \\
(80.1-84.4)\end{array}$ & $\begin{array}{c}84.6 \\
(81.6-87.6)\end{array}$ & $\begin{array}{c}76.6 \\
(74.6-78.5)\end{array}$ & $\begin{array}{c}72.4 \\
(68.8-76.0)\end{array}$ & $\begin{array}{c}74.7 \\
(71.2-78.3)\end{array}$ & B \\
\hline Ever had sex ${ }^{b}$ & $\begin{array}{c}35.7 \\
(32.3-39.1)\end{array}$ & $\begin{array}{c}40.7 \\
(34.4-46.9)\end{array}$ & $\begin{array}{c}42.0 \\
(38.7-45.4)\end{array}$ & $\begin{array}{c}47.0 \\
(41.1-52.8)\end{array}$ & $\begin{array}{c}53.0 \\
(47.0-59.1)\end{array}$ & C \\
\hline Ever been pregnant ${ }^{b}$ & $\begin{array}{c}14.7 \\
(12.2-17.2)\end{array}$ & $\begin{array}{c}15.8 \\
(11.3-20.3)\end{array}$ & $\begin{array}{c}12.8 \\
(10.6-15.0)\end{array}$ & $\begin{array}{c}14.5 \\
(10.5-18.5)\end{array}$ & $\begin{array}{c}16.5 \\
(12.2-20.9)\end{array}$ & \\
\hline Ever given birth ${ }^{b}$ & $\begin{array}{c}11.9 \\
(9.7-14.2)\end{array}$ & $\begin{array}{c}12.6 \\
(8.6-16.7)\end{array}$ & $\begin{array}{c}9.8 \\
(7.8-11.7)\end{array}$ & $\begin{array}{c}12.2 \\
(8.4-15.9)\end{array}$ & $\begin{array}{c}10.8 \\
(7.1-14.4)\end{array}$ & \\
\hline HIV positive ${ }^{b}$ & $\begin{array}{c}1.8 \\
(0.9-2.7)\end{array}$ & $\begin{array}{c}2.4 \\
(0.5-4.4)\end{array}$ & $\begin{array}{c}4.5 \\
(3.1-5.9)\end{array}$ & $\begin{array}{c}3.2 \\
(1.1-5.2)\end{array}$ & $\begin{array}{c}6.0 \\
(3.1-8.8)\end{array}$ & \\
\hline \multicolumn{7}{|l|}{ Parent level } \\
\hline Mother is alive & $\begin{array}{c}89.8 \\
(88.4-91.3)\end{array}$ & $\begin{array}{c}88.1 \\
(85.5-90.8)\end{array}$ & $\begin{array}{c}85.4 \\
(83.7-87.0)\end{array}$ & $\begin{array}{c}85.9 \\
(83.1-88.8)\end{array}$ & $\begin{array}{c}85.7 \\
(82.9-88.6)\end{array}$ & \\
\hline Father is alive & $\begin{array}{c}79.9 \\
(78.0-81.8)\end{array}$ & $\begin{array}{c}80.7 \\
(77.4-83.9)\end{array}$ & $\begin{array}{c}71.7 \\
(69.6-73.8)\end{array}$ & $\begin{array}{c}71.3 \\
(67.7-75.0)\end{array}$ & $\begin{array}{c}74.4 \\
(70.8-78.0)\end{array}$ & \\
\hline Mother is coresident ${ }^{c}$ & $\begin{array}{c}77.6 \\
(75.6-79.7)\end{array}$ & $\begin{array}{c}83.7 \\
(80.5-87.0)\end{array}$ & $\begin{array}{c}70.8 \\
(68.5-73.1)\end{array}$ & $\begin{array}{c}71.3 \\
(67.3-75.2)\end{array}$ & $\begin{array}{c}66.1 \\
(61.9-70.2)\end{array}$ & $A, C$ \\
\hline Father is coresident ${ }^{c}$ & $\begin{array}{c}64.0 \\
(61.4-66.5)\end{array}$ & $\begin{array}{c}71.0 \\
(66.8-75.2)\end{array}$ & $\begin{array}{c}58.8 \\
(56.1-61.4)\end{array}$ & $\begin{array}{c}53.6 \\
(48.8-58.4)\end{array}$ & $\begin{array}{c}56.7 \\
(60.0-61.4)\end{array}$ & A \\
\hline $\begin{array}{l}\text { Mother completed } \\
\text { grade } 7\end{array}$ & $\begin{array}{c}44.1 \\
(41.8-46.5)\end{array}$ & $\begin{array}{c}42.8 \\
(38.8-46.9)\end{array}$ & $\begin{array}{c}45.5 \\
(43.2-47.8)\end{array}$ & $\begin{array}{c}43.6 \\
(39.5-47.6)\end{array}$ & $\begin{array}{c}49.0 \\
(44.9-53.0)\end{array}$ & \\
\hline $\begin{array}{l}\text { Father completed } \\
\text { grade } 7\end{array}$ & $\begin{array}{c}52.2 \\
(49.9-54.6)\end{array}$ & $\begin{array}{c}54.3 \\
(50.2-58.4)\end{array}$ & $\begin{array}{c}48.2 \\
(45.9-50.5)\end{array}$ & $\begin{array}{c}47.9 \\
(43.8-51.9)\end{array}$ & $\begin{array}{c}51.7 \\
(47.7-55.8)\end{array}$ & \\
\hline \multicolumn{7}{|l|}{ Household level } \\
\hline $\begin{array}{l}\text { Girl is biological daughter } \\
\text { of household head }\end{array}$ & $\begin{array}{c}68.2 \\
(66.0-70.4)\end{array}$ & $\begin{array}{c}70.8 \\
(67.0-74.5)\end{array}$ & $\begin{array}{c}60.7 \\
(58.5-63.0)\end{array}$ & $\begin{array}{c}57.2 \\
(53.2-61.2)\end{array}$ & $\begin{array}{c}57.4 \\
(53.3-61.4)\end{array}$ & \\
\hline Asset items (mean) ${ }^{d}$ & $\begin{array}{c}5.3 \\
(5.1-5.4)\end{array}$ & $\begin{array}{c}5.0 \\
(4.8-5.2)\end{array}$ & $\begin{array}{c}6.4 \\
(6.3-6.5)\end{array}$ & $\begin{array}{c}6.6 \\
(6.3-6.8)\end{array}$ & $\begin{array}{c}7.0 \\
(6.7-7.2)\end{array}$ & C, D \\
\hline $\begin{array}{l}\text { Savings/assets worth at } \\
\text { least KW } 100\end{array}$ & $\begin{array}{c}60.0 \\
(57.7-62.3)\end{array}$ & $\begin{array}{c}64.1 \\
(60.1-68.1)\end{array}$ & $\begin{array}{c}63.1 \\
(60.8-65.3)\end{array}$ & $\begin{array}{c}63.2 \\
(59.3-67.2)\end{array}$ & $\begin{array}{c}66.0 \\
(62.1-69.8)\end{array}$ & \\
\hline $\begin{array}{l}\text { Savings/assets worth at } \\
\text { least KW } 500\end{array}$ & $\begin{array}{c}24.1 \\
(22.1-26.2)\end{array}$ & $\begin{array}{c}32.0 \\
(28.1-35.8) \\
\end{array}$ & $\begin{array}{c}28.1 \\
(26.0-30.2)\end{array}$ & $\begin{array}{c}28.2 \\
(25.6-31.9)\end{array}$ & $\begin{array}{c}31.5 \\
(27.7-35.3)\end{array}$ & A \\
\hline
\end{tabular}

A Statistically significant difference between (1) and (2), p <.05

B Statistically significant difference between (3) and (4), $p<.05$

C Statistically significant difference between (3) and (5), $p<.05$

D Statistically significant difference between (4) and (5), $p<.05$

Notes: Two-sided Z-tests for proportions and T-tests for means were used. Data are preliminary and subject to minor revisions. Ns may be smaller than reported due to missing values.

a If ever attended school

b Ages 15-19 only

$c$ If parent is alive

${ }^{a}$ Out of the following 15 items: electricity/solar panels, radio, cassette player, television, mobile phone, fixed phone, refrigerator, table, sofa, bed, CD/digital music player, VCR/DVD player, car, motorcycle, bicycle 
As indicated in the table, the differences between the programme and internal control arms within rural areas (column $6-\mathrm{A}$ ) and urban areas (column 6 - B) are marginal and insignificant in all but 4 of the 18 indicators. ${ }^{7}$ Across the array of respondent, parental and household level indicators, it appears that the AGEP and internal control arms are well balanced. Parental co-residency is significantly higher in the internal controls in rural areas relative to the rural programme areas, although there are no differences in parental survivorship or educational attainment. For urban areas, current school attendance is statistically different between the programme and internal controls by approximately $4 \%$, with higher attendance rates in the former, however, other educational indicators, such as ever attended school and highest grade completed are not significantly different. These results suggest that there are no systematic differences at baseline across programme and controls within a particular domain.

Comparisons between the programme and external control arms in urban areas (column 6 C) are also significantly different in 4 of the 18 indicators. Girls in the external controls are significantly less likely to have ever attended school, more likely to have ever had sex and less likely to have a mother co-resident in the household than girls in the programme arms. The difference, however, is relatively small for ever having attended school. Girls in the external control areas are also more likely, although not significantly so, to have been pregnant, given birth and acquired HIV. These results suggest that girls in the external control at baseline may be more disadvantaged and may have begun to experience unfavourable life outcomes. This conclusion, however, must be moderated by the higher average number of assets in the household, also an indicator of the socioeconomic status, in the external control arm. These findings will require exploration and consideration in further analyses that account for both observable and unobservable differences between programme and external controls.

Finally, with the exception of household assets (column 6 - D), there are no statistically significant differences between the internal and external controls groups across the array of sociodemographic and behavioural indicators. That said, a notable finding is the higher HIV prevalence in the external controls, although this difference does not reach statistical significance at the $p<.05$ level. This finding is consistent with the higher rates of sexual intiation in the external control areas.

Overall, the baseline non-response in Table 10 and the comparison of socioeconomic and behavioural characteristics by study arm in Table 11 are reassuring that the sampling processes and fieldwork implementation were successful in achieving a balanced distribution of the adolescent population in the study. Although the study must be mindful of the potential for differential attrition by study arm over time, these baseline results provide a degree of confidence that the study is well positioned to use the sample to effectively assess programme impact.

\footnotetext{
${ }^{7}$ It should be noted that for 18 indicators, the probability of at least one being significant by chance alone is $60 \%$, conversely, the probability all the indicators would be insignificant at $p<.05$ is only $40 \%$.
} 
Table 12: Comparison of key baseline characteristics by age and residence; \% (95\% confidence interval)

\begin{tabular}{|c|c|c|c|c|c|c|c|c|}
\hline Indicator & $\begin{array}{c}(1) \\
\text { All } \\
\text { respondents } \\
(\mathrm{N}=4668)\end{array}$ & $\begin{array}{c}(2) \\
\text { Total } \\
\text { Age 10-14 } \\
(\mathrm{N}=2418)\end{array}$ & $\begin{array}{c}(3) \\
\text { Total } \\
\text { Age 15-19 } \\
(\mathrm{N}=2250)\end{array}$ & $\begin{array}{c}(4) \\
\text { Age 10-14, } \\
\text { Rural } \\
(\mathrm{N}=1219)\end{array}$ & $\begin{array}{c}(5) \\
\text { Age 10-14, } \\
\text { Urban } \\
(\mathrm{N}=1199)\end{array}$ & $\begin{array}{c}(6) \\
\text { Age 15-19, } \\
\text { Rural } \\
(\mathrm{N}=1056)\end{array}$ & $\begin{array}{c}(7) \\
\text { Age 15-19, } \\
\text { Urban } \\
(\mathrm{N}=1194)\end{array}$ & $\begin{array}{c}(8) \\
\text { Statistically } \\
\text { significant } \\
\text { differences } \\
(p<.05)\end{array}$ \\
\hline \multicolumn{9}{|l|}{ Parent characteristics } \\
\hline Mother died & $\begin{array}{c}12.6 \\
(11.6-13.5)\end{array}$ & $\begin{array}{c}9.3 \\
(8.1-10.4)\end{array}$ & $\begin{array}{c}16.2 \\
(14.7-17.7)\end{array}$ & $\begin{array}{c}7.6 \\
(6.1-9.1)\end{array}$ & $\begin{array}{c}10.9 \\
(9.2-12.7)\end{array}$ & $\begin{array}{c}14.0 \\
(11.9-16.1)\end{array}$ & $\begin{array}{c}18.1 \\
(15.9-20.3)\end{array}$ & $A, B, C$ \\
\hline Father died & $\begin{array}{c}24.3 \\
(23.0-25.5)\end{array}$ & $\begin{array}{c}20.6 \\
(19.0-22.2)\end{array}$ & $\begin{array}{c}28.2 \\
(26.4-30.1)\end{array}$ & $\begin{array}{c}16.9 \\
(14.8-19.0)\end{array}$ & $\begin{array}{c}24.4 \\
(21.9-26.8)\end{array}$ & $\begin{array}{c}23.4 \\
(20.9-26.0)\end{array}$ & $\begin{array}{c}32.4 \\
(29.8-35.0)\end{array}$ & $A, B, C$ \\
\hline Both parents died & $\begin{array}{c}6.6 \\
(5.9-7.4)\end{array}$ & $\begin{array}{c}4.6 \\
(3.8-5.5)\end{array}$ & $\begin{array}{c}8.8 \\
(7.6-10.0)\end{array}$ & $\begin{array}{c}3.8 \\
(2.7-4.8)\end{array}$ & $\begin{array}{c}5.5 \\
(4.2-6.8)\end{array}$ & $\begin{array}{c}7.1 \\
(5.6-8.6)\end{array}$ & $\begin{array}{c}10.3 \\
(8.6-12.0)\end{array}$ & $A, B, C$ \\
\hline Living with mother & $\begin{array}{c}65.6 \\
(64.2-66.9)\end{array}$ & $\begin{array}{c}68.1 \\
(66.2-69.9)\end{array}$ & $\begin{array}{c}62.8 \\
(60.8-64.8)\end{array}$ & $\begin{array}{c}72.3 \\
(69.8-74.8)\end{array}$ & $\begin{array}{c}63.8 \\
(61.0-66.5)\end{array}$ & $\begin{array}{c}68.9 \\
(66.1-71.7)\end{array}$ & $\begin{array}{c}57.5 \\
(54.6-60.3)\end{array}$ & $A, B, C$ \\
\hline $\begin{array}{l}\text { Living with neither } \\
\text { parent }\end{array}$ & $\begin{array}{c}30.2 \\
(28.9-31.5)\end{array}$ & $\begin{array}{c}27.6 \\
(25.9-29.4)\end{array}$ & $\begin{array}{c}32.9 \\
(31.0-34.9)\end{array}$ & $\begin{array}{c}23.4 \\
(21.0-25.8)\end{array}$ & $\begin{array}{c}32.0 \\
(29.3-34.6)\end{array}$ & $\begin{array}{c}27.6 \\
(24.9-30.3)\end{array}$ & $\begin{array}{c}37.7 \\
(34.9-40.4)\end{array}$ & $A, B, C$ \\
\hline \multicolumn{9}{|l|}{ Schooling } \\
\hline $\begin{array}{l}\text { Currently attending } \\
\text { school }\end{array}$ & $\begin{array}{c}79.2 \\
(78.1-80.4)\end{array}$ & $\begin{array}{c}89.4 \\
(88.2-90.6)\end{array}$ & $\begin{array}{c}68.3 \\
(66.3-70.2)\end{array}$ & $\begin{array}{c}92.8 \\
(91.3-94.2)\end{array}$ & $\begin{array}{c}86.0 \\
(84.0-88.0)\end{array}$ & $\begin{array}{c}71.9 \\
(69.2-74.6)\end{array}$ & $\begin{array}{c}65.1 \\
(62.4-67.8)\end{array}$ & $A, B, C$ \\
\hline Completed Grade 7 & -- & -- & $\begin{array}{c}68.7 \\
(66.7-70.6)\end{array}$ & -- & -- & $\begin{array}{c}72.2 \\
(69.4-74.9)\end{array}$ & $\begin{array}{c}65.6 \\
(62.9-68.3)\end{array}$ & C \\
\hline Completed Grade 9 & - & - & $\begin{array}{c}22.0 \\
(20.3-23.7)\end{array}$ & -- & -- & $\begin{array}{c}25.5 \\
(22.9-28.2)\end{array}$ & $\begin{array}{c}18.9 \\
(16.6-21.1)\end{array}$ & C \\
\hline \multicolumn{9}{|c|}{ Financial literacy and savings } \\
\hline $\begin{array}{l}\text { Financial planning and } \\
\text { budgeting score } \\
\text { (mean; max 10) }\end{array}$ & $\begin{array}{c}5.3 \\
(5.3-5.4)\end{array}$ & $\begin{array}{c}4.7 \\
(4.6-4.8)\end{array}$ & $\begin{array}{c}6.0 \\
(6.0-6.1)\end{array}$ & $\begin{array}{c}4.6 \\
(4.5-4.7)\end{array}$ & $\begin{array}{c}4.8 \\
(4.7-4.9)\end{array}$ & $\begin{array}{c}5.9 \\
(5.8-6.0)\end{array}$ & $\begin{array}{c}6.2 \\
(6.0-6.3)\end{array}$ & $A, C$ \\
\hline $\begin{array}{l}\text { Saved money in past } \\
\text { year }\end{array}$ & $\begin{array}{c}14.9 \\
(13.9-15.9)\end{array}$ & $\begin{array}{c}10.5 \\
(9.2-11.7)\end{array}$ & $\begin{array}{c}19.6 \\
(17.9-21.2)\end{array}$ & $\begin{array}{c}10.1 \\
(8.4-11.8)\end{array}$ & $\begin{array}{c}10.9 \\
(9.2-12.7)\end{array}$ & $\begin{array}{c}17.5 \\
(15.2-19.8)\end{array}$ & $\begin{array}{c}21.4 \\
(19.0-23.7)\end{array}$ & $A, C$ \\
\hline
\end{tabular}


Table 12 (continued). Comparison of key baseline characteristics by age and residence; \% (95\% confidence interval)

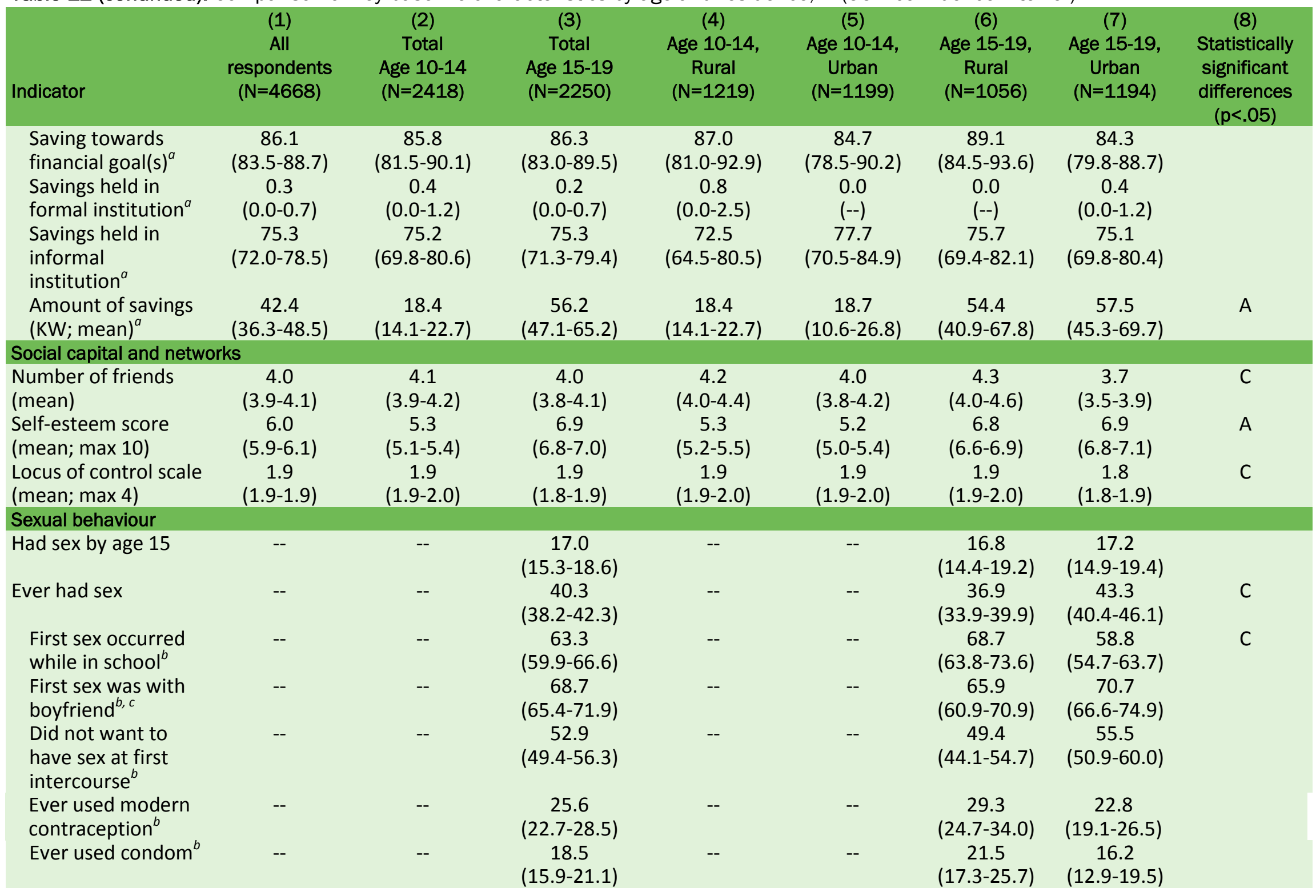


Table 12 (continued). Comparison of key baseline characteristics by age and residence; \% (95\% confidence interval)

\begin{tabular}{|c|c|c|c|c|c|c|c|c|}
\hline Indicator & $\begin{array}{c}(1) \\
\text { All } \\
\text { respondents } \\
(\mathrm{N}=4668)\end{array}$ & $\begin{array}{c}(2) \\
\text { Total } \\
\text { Age 10-14 } \\
(\mathrm{N}=2418)\end{array}$ & $\begin{array}{c}(3) \\
\text { Total } \\
\text { Age 15-19 } \\
(\mathrm{N}=2250)\end{array}$ & $\begin{array}{c}(4) \\
\text { Age 10-14, } \\
\text { Rural } \\
(\mathrm{N}=1219)\end{array}$ & $\begin{array}{c}(5) \\
\text { Age 10-14, } \\
\text { Urban } \\
(\mathrm{N}=1199)\end{array}$ & $\begin{array}{c}(6) \\
\text { Age } 15-19, \\
\text { Rural } \\
(\mathrm{N}=1056)\end{array}$ & $\begin{array}{c}(7) \\
\text { Age 15-19, } \\
\text { Urban } \\
(\mathrm{N}=1194)\end{array}$ & $\begin{array}{c}(8) \\
\text { Statistically } \\
\text { significant } \\
\text { differences } \\
(p<.05)\end{array}$ \\
\hline \multicolumn{9}{|l|}{ Pregnancy \& childbearing } \\
\hline Ever been pregnant & -- & -- & $\begin{array}{c}14.0 \\
(12.6-15.5)\end{array}$ & -- & -- & $\begin{array}{c}15.0 \\
(12.8-17.1)\end{array}$ & $\begin{array}{c}13.2 \\
(11.3-15.1)\end{array}$ & \\
\hline $\begin{array}{l}\text { First pregnancy } \\
\text { occurred while in } \\
\text { school }^{d}\end{array}$ & -- & -- & $\begin{array}{c}57.5 \\
(52.0-63.0)\end{array}$ & -- & -- & $\begin{array}{c}69.2 \\
(62.0-76.5)\end{array}$ & $\begin{array}{c}45.9 \\
(38.1-53.7)\end{array}$ & C \\
\hline $\begin{array}{l}\text { Did not receive } \\
\text { antenatal care }^{d}\end{array}$ & -- & -- & $\begin{array}{c}10.0 \\
(6.6-13.4)\end{array}$ & -- & -- & $\begin{array}{c}9.7 \\
(5.0-14.4)\end{array}$ & $\begin{array}{c}10.3 \\
(5.5-15.1)\end{array}$ & \\
\hline $\begin{array}{l}\text { Ever experienced } \\
\text { unwanted pregnancy }\end{array}$ & -- & -- & $\begin{array}{c}11.4 \\
(10.1-12.8)\end{array}$ & -- & -- & $\begin{array}{c}12.1 \\
(10.0-14.1)\end{array}$ & $\begin{array}{c}10.8 \\
(9.0-12.7)\end{array}$ & \\
\hline Ever given birth & -- & -- & $\begin{array}{c}11.2 \\
(9.9-12.5)\end{array}$ & -- & -- & $\begin{array}{c}12.1 \\
(10.1-14.1)\end{array}$ & $\begin{array}{c}10.4 \\
(8.6-12.1)\end{array}$ & \\
\hline \multicolumn{9}{|l|}{ Marriage } \\
\hline $\begin{array}{l}\text { Ever been married } \\
\text { Expected age at } \\
\text { marriage }^{\text {e }}\end{array}$ & $\begin{array}{c}0.0 \\
--\end{array}$ & $\begin{array}{c}0.0 \\
--\end{array}$ & $\begin{array}{c}0.0 \\
25.0 \\
(24.8-25.2)\end{array}$ & $\begin{array}{c}0.0 \\
--\end{array}$ & $\begin{array}{c}0.0 \\
--\end{array}$ & $\begin{array}{c}0.0 \\
24.9 \\
(24.6-25.2)\end{array}$ & $\begin{array}{c}0.0 \\
25.0 \\
(24.8-25.3)\end{array}$ & \\
\hline \multicolumn{9}{|c|}{ Sexual and reproductive health } \\
\hline $\begin{array}{l}\text { SRH knowledge score } \\
\text { (mean; max 9) }\end{array}$ & $\begin{array}{c}2.3 \\
(2.2-2.3)\end{array}$ & $\begin{array}{c}1.0 \\
(0.9-1.0)\end{array}$ & $\begin{array}{c}3.7 \\
(3.6-3.8)\end{array}$ & $\begin{array}{c}1.0 \\
(0.9-1.1)\end{array}$ & $\begin{array}{c}1.0 \\
(0.9-1.1)\end{array}$ & $\begin{array}{c}3.7 \\
(3.6-3.8)\end{array}$ & $\begin{array}{c}3.6 \\
(3.5-3.7)\end{array}$ & A \\
\hline $\begin{array}{l}\text { HIV/AIDS knowledge } \\
\text { score (mean; max 11) }\end{array}$ & $\begin{array}{c}5.8 \\
(5.7-5.9)\end{array}$ & $\begin{array}{c}4.3 \\
(4.1-4.4)\end{array}$ & $\begin{array}{c}7.5 \\
(7.3-7.6)\end{array}$ & $\begin{array}{c}4.4 \\
(4.2-4.6)\end{array}$ & $\begin{array}{c}4.2 \\
(4.0-4.4)\end{array}$ & $\begin{array}{c}7.5 \\
(7.3-7.6)\end{array}$ & $\begin{array}{c}7.5 \\
(7.3-7.6)\end{array}$ & A \\
\hline Ever had HIV test ${ }^{f}$ & -- & -- & $\begin{array}{c}30.7 \\
(28.8-32.6)\end{array}$ & -- & -- & $\begin{array}{c}29.4 \\
(26.7-32.2)\end{array}$ & $\begin{array}{c}31.8 \\
(29.2-34.5)\end{array}$ & \\
\hline HIV positive & -- & -- & $\begin{array}{c}3.1 \\
(2.4-3.8)\end{array}$ & -- & -- & $\begin{array}{c}1.9 \\
(1.1-2.8)\end{array}$ & $\begin{array}{c}4.2 \\
(3.0-5.4)\end{array}$ & C \\
\hline $\begin{array}{l}\text { Covered by health } \\
\text { insurance scheme }\end{array}$ & $\begin{array}{c}1.8 \\
(1.4-2.1)\end{array}$ & $\begin{array}{c}1.6 \\
(1.1-2.1)\end{array}$ & $\begin{array}{c}2.0 \\
(1.4-2.5)\end{array}$ & $\begin{array}{c}1.3 \\
(0.7-2.0)\end{array}$ & $\begin{array}{c}1.8 \\
(1.1-2.6)\end{array}$ & $\begin{array}{c}2.2 \\
(1.3-3.1)\end{array}$ & $\begin{array}{c}1.8 \\
(1.0-2.5)\end{array}$ & \\
\hline
\end{tabular}


Table 12 (continued). Comparison of key baseline characteristics by age and residence; \% (95\% confidence interval)

\begin{tabular}{|c|c|c|c|c|c|c|c|c|}
\hline Indicator & $\begin{array}{c}(1) \\
\text { All } \\
\text { respondents } \\
(\mathrm{N}=4668)\end{array}$ & $\begin{array}{c}(2) \\
\text { Total } \\
\text { Age } 10-14 \\
(\mathrm{~N}=2418)\end{array}$ & $\begin{array}{c}(3) \\
\text { Total } \\
\text { Age } 15-19 \\
(\mathrm{~N}=2250)\end{array}$ & $\begin{array}{c}(4) \\
\text { Age 10-14, } \\
\text { Rural } \\
(\mathrm{N}=1219)\end{array}$ & $\begin{array}{c}(5) \\
\text { Age 10-14, } \\
\text { Urban } \\
(\mathrm{N}=1199)\end{array}$ & $\begin{array}{c}(6) \\
\text { Age 15-19, } \\
\text { Rural } \\
(\mathrm{N}=1056)\end{array}$ & $\begin{array}{c}(7) \\
\text { Age 15-19, } \\
\text { Urban } \\
(\mathrm{N}=1194)\end{array}$ & $\begin{array}{c}(8) \\
\text { Statistically } \\
\text { significant } \\
\text { differences } \\
(p<.05)\end{array}$ \\
\hline \multicolumn{9}{|c|}{ Experience of physical and sexual violence } \\
\hline $\begin{array}{l}\text { Experienced physical } \\
\text { violence in past } 12 \\
\text { months }\end{array}$ & $\begin{array}{c}38.0 \\
(36.3-39.6)\end{array}$ & $\begin{array}{c}40.3^{g} \\
(37.4-43.3)\end{array}$ & $\begin{array}{c}36.8 \\
(34.8-38.8)\end{array}$ & $\begin{array}{c}37.9^{g} \\
(33.9-42.0)\end{array}$ & $\begin{array}{c}43.1^{g} \\
(38.7-47.5)\end{array}$ & $\begin{array}{c}37.0 \\
(34.1-39.9)\end{array}$ & $\begin{array}{c}36.7 \\
(33.9-39.4)\end{array}$ & \\
\hline $\begin{array}{l}\text { Ever forced to perform } \\
\text { sex act }\end{array}$ & -- & -- & $\begin{array}{c}20.7 \\
(19.0-22.4)\end{array}$ & -- & -- & $\begin{array}{c}20.8 \\
(18.4-23.3)\end{array}$ & $\begin{array}{c}20.6 \\
(18.3-22.9)\end{array}$ & \\
\hline
\end{tabular}

A Statistically significant difference between (2) and (3), $p<.05$

B Statistically significant difference between (4) and (5), $p<.05$

C Statistically significant difference between (6) and (7), $p<.05$

a If saved money in past year

${ }^{b}$ If ever had sex

c Other partner types include: sugar daddy, casual acquaintance, relative, teacher, or someone else.

$d$ If ever been pregnant

e Excludes girls who indicated they did not expect to get married, or did not know their expected age at marriage.

$f$ Does not include HIV test conducted as part of this study

g Ages 13-14 only

Notes: External control sites excluded for these comparisons. Statistically significant difference determined using two-sided Z-tests for proportions and

T-tests for means. Data are preliminary and subject to minor revisions. Ns may be smaller than reported due to missing values. 
Table 12 provides an overview of the sample characteristics at baseline by age and residential status. The primary statistical comparisons in the table are between the two age groups (column 2 versus 3 - A) and between urban and rural for the 10-14 year-olds (column 4 versus $5-\mathrm{B}$ ) and 15-19 year-olds (column 6 versus $7-\mathrm{C}$ ). A selection of the findings from the table is discussed below.

The first panel of the table indicates that, not surprisingly, older adolescents are significantly more likely to have one or more deceased parents than younger adolescents. In all cases, the father is more likely to have died than the mother. Both parents of around $5 \%$ of adolescents aged 10-14 and 9\% of those 15-19 are deceased. These numbers are comparable for similar age groups in the 2007 DHS, where approximately $6 \%$ of adolescents among the younger age group and 9\% among the older age group have both parents deceased. ${ }^{8}$ The results presented in Table 12 also indicate that nearly one in three adolescents do not live with either parent during this critical time of life.

As can be observed from the schooling indicators, the vast majority of 10-14 year-olds (89\%) were attending school at the time of the survey. Interestingly, the proportion currently attending school in rural areas was higher than in urban areas for both age groups. This observation runs counter to patterns typically seen in representative population samples in developing countries, such as the Demographic and Health Surveys, where urban populations tend to be better off than their rural counterparts. For instance, in the 1992, 1996 and 2001 Zambia DHS $^{9}$, adolescent girls in rural areas were significantly less likely to currently attend school than girls in urban areas. This pattern of findings is also evident in the grade completion indicator, where rural adolescents are significantly more likely to complete grade 7 than urban adolescents. These results point to the particular nature of the AGEP research sample, specifically targeting the most vulnerable adolescents.

As explained earlier, girls were recruited into AGEP on the basis of a vulnerability score, with the most vulnerable girls selected for participation. As population density in urban areas is much higher than in rural areas, a smaller proportion of eligible girls in the urban areas than in the rural are included in the research sampling frame, as can be observed in Table 6 (page 16). While girls selected in urban areas represent the 30 to $50 \%$ of the most vulnerable girls in these areas, girls selected in rural areas represent a much wider range, between 70 to $100 \%$, of girls residing in the area. Thus, while girls in rural areas are more representative of girls in rural areas more generally, the girls selected for AGEP in urban areas can be considered relatively worse off. For some indicators, these girls may have poorer outcomes than their rural counterparts; for example parental survivorship.

In Table 12, girls in the older age cohort demonstrated significantly greater competency in financial literacy by answering more questions related to budgeting, planning, and saving than their younger counterparts. This difference was also reflected in actual savings practices: $18 \%$ and $21 \%$ of $15-19$ year-olds in rural and urban areas, respectively, reported setting money aside during the past year for future expenditures compared with $10 \%$ (rural)

\footnotetext{
${ }^{8}$ The DHS age bracket for the older age group is $15-17$ as they do not count those who have reached the age of emancipation as children.

${ }^{9}$ Similar data were not obtained in the 2007 Zambia DHS.
} 
and $11 \%$ (urban) of girls in the younger age group. This difference likely reflects the relative opportunity for older girls to work outside of the household and to earn money, particularly in urban areas. It will be important to note moving forward whether such opportunities translate into positive outcomes for urban adolescents. Girls aged 15-19 were also more likely to have a greater amount of money set aside. These numbers are expected to rise substantially as AGEP gets underway.

A large divide was also observed across age groups for reported self-esteem. When asked a series of ten questions about their ability to accomplish tasks and achieve goals, 15-19 year-olds were significantly more likely to respond positively than their younger counterparts. The older girls did not, however, report having more friends, with nearly the same numbers observed across age groups. Urban 15-19 year-olds had on average 3.7 male and female friends, signficantly fewer than the average number (4.3) observed among their same-age peers in rural areas. Similarly, on a four-item locus of control scale, the older urban cohort was slightly less likely to report feeling in control of life events, but rather felt a greater influence by external forces or chance; perhaps reflective of greater instability in their lives.

As noted earlier, 10-14 year-olds were not asked about sexual behaviour. A significant proportion of the 15-19 year-old sample (40\%) had initiated sexual activity by the baseline survey, with a significantly greater prevalence of premarital sex in urban (43\%) than rural (37\%) areas. This finding is lower than the percent reporting sexual activity in the 2007 DHS (48\% among those 15-19); although interestingly, a greater proportion of girls had sex by age $15(17 \%)$ in the AGEP sample, than in the 2007 DHS (12\%). These results suggest that adolescents in the sample are less likely to intiate sexual activity, but if they do, they report doing so at a younger age than do those in the DHS. The large percentage of girls reporting unwanted sexual initiation (53\%) is perhaps telling in this regard. Finally, a majority of adolescents who reported having had sex indicated that they first did so while attending school. Given limited condom use, the impact of pregnancy on schooling attendance and attainment needs be considered. The high rates of pregnancy (14\%) and unwanted pregnancy $(11 \%)$ also suggest that girls in the sample are facing negative outcomes as a consequence of early sexual initiation.

With respect to sexual and reproductive health knowledge, the younger cohort demonstrated significantly less familiarity with these topics than did their older counterparts ${ }^{10}$, although both age groups demonstrate an overall lack of knowledge. Awareness of HIV and its causes was higher across all groups, but 10-14 year-olds were significantly less knowledgeable than their older peers. No differences by residence were observed for either of the knowledge indicators. HIV prevalence was considerably higher in urban than in rural areas (4\% vs. 2\%). HIV prevalence among girls ages 15-19 in the AGEP sample was lower than that observed among the same aged girls in the 2007 Zambia DHS (6\%). That said, this difference may reflect trends in HIV over the previous seven years since the DHS survey was conducted.

\footnotetext{
${ }^{10} \mathrm{SRH}$ knowledge was measured as being able to identify the time of the menstrual period in which pregnancy is most likely and being aware of various methods of contraception.
} 
More than one-third of girls (38\%) across all groups reported being hit, slapped or kicked at least once in the past year. The percent of victims of violence in the AGEP research sample among 15-19 year-olds (37\%) matches the percent among the same age group observed in the 2007 Zambia DHS. The highest prevalence of violence in the preceding 12 months was reported by 10-14 year-old girls in urban areas at $43 \%$, however, at all ages and in all areas, a considerable proportion of girls are exposed to physical violence. Moreover, more than one in five adolescent girls have been forced to perform a sex act, with very little difference in these events between rural and urban areas.

\section{Addressing Spillovers}

A concern when measuring the impact of AGEP is the potential for intervention spillover effects across experimental and across control and experimental areas. If spillovers occur, the difference between programme and control arm outcomes may understate the true programme effects. Although, by design, the AGEP intervention components (safe spaces, health vouchers and savings accounts) are fundamentally excludable from girls that have not been selected for the programme or certain components of the programme, knowledge transfers may occur through social networks. In urban areas, such transfers may occur because AGEP is implemented in smaller geographic spaces, while in rural areas, such transfers may occur because a much greater proportion of the girls in the master sites are selected to participate.

To address these issues, measures were included at baseline to capture the extent of overlap in key social spaces, particularly schools and churches. This information can then be parsed by the different programme and control arms to measure the potential for spillover effects. Data on social networks was also collected, allowing us to match the names of the AGEP girls' closest friends with the names of girls participating in other study arms for a more exact assessment. As data collection was just completed in February 2014, this data has not yet been processed and analysed. The processes and effects of spillover will also be assessed using the qualitative data, where girls are being asked to describe with whom they share AGEP-related information, the nature of the information shared, as well as the circumstances surrounding the exchange. In the following survey rounds, after AGEP has been implemented for some time, specific questions will be asked in the control arms to measure the extent to which they have been exposed to AGEP.

\section{Economic Evaluation}

The following activities have been carried out at baseline under each component of the economic evaluation:

Costs of programme implementation: A range of programme costs were incurred during the implementation of AGEP between November 2012 and November 2013 and were collected from the project budgets and expenditure reports of the Population Council, YWCA Zambia, and NatSave for the 'Safe Spaces', Health Voucher, and Savings Account components, respectively. An "ingredients approach" was used, whereby quantities and unit costs of all resource items were identified. A data entry tool was developed in Microsoft Excel, in which 
costs are grouped according to the following functional classification: staff, buildings (rentals and ownership), vehicles, utilities and insurance, supplies and services, and food, accommodation and travel. This enables us to determine which programme elements are the most significant drivers of total costs in each trial arm. Expenditures were divided into capital and recurring costs. Capital costs include durable items such as buildings, vehicles, and IT equipment. Present values and life expectancies of capital items were approximated from procurement lists and by consulting staff in charge. Item costs are annualised by $9 \%$ per year in line with the Bank of Zambia's policy rate. Average recurring costs will be estimated from the expense records from Years1, 2, and 3.

Once programme implementation is terminated in the last quarter of 2015, these data will enable the calculation of incremental costs for each arm of the AGEP evaluation trial ('Safe spaces' only; 'Safe Spaces' + Health Voucher; 'Safe Spaces' + Health Voucher + Savings Account). Total costs will be divided by the number of participants in order to estimate the costs per girl and results will be presented by trial arm and by programme site (urban vs. rural).

Participant direct and indirect costs: Questions on the direct, out-of-pocket costs of programme participation and on the indirect, opportunity costs were developed and piloted for inclusion in the baseline survey. The questions elicit information on out-of-pocket expenses incurred while participating in 'Safe Spaces,' visiting health facilities to redeem the health voucher, or going to the bank to open and use the savings account. Other questions encompass the opportunity costs of taking part in AGEP, including lost income and time that would have otherwise been spent on unpaid work and other productive activities within the household.

Health provider costs: The absence of routine cost data collection systems within the Zambian Ministry of Health implies that, in order to assess the costs of health services, micro-costing of specific health facilities is required. Two programme facilities were selected to take part in a micro-costing exercise: Chawama clinic in Lusaka District and Luanshimba health centre in Kapiri-Mposhi District. The 'ingredients approach' will again be followed to identify all resource items that are used in the production of the health services offered through the Voucher scheme and their prices. The costing year will be 2012 as it is the most recent year for which all facility records have been compiled.

A data collection and analysis spreadsheet was developed in Microsoft Excel and overhead costs, defined as the shared costs that are common to all services provided at the facility (e.g. administrative staff, maintenance, laundry services etc.) have been collected for Chawama clinic from August to September 2013. The same techniques for valuing resources and annualising capital costs described for programme costs will be followed. Provider costs at Luanshimba health centre will be collected during June 2014. Costs per girl estimates will be calculated at the end of the programme, once the figures on services usage become available. 


\section{Baseline Challenges and Lessons Learned}

All large research studies face challenges and this is no less the case for AGEP, which, in addition to being a complex intervention, is a very comprehensive research endeavor. The baseline data collection effort included a survey conducted among 81,000 households, over 6,800 adolescents to be tracked and interviewed, anthropometric data collected for participants and their children, and biological specimens collected for HIV and HSV-2. Informed consent was required from parents/guardians for adolescents aged 10-17 and proper counseling and referals in place for sexually trasmitted infection and reports of violence.

Below are a selection of some of the key challenges faced during the baseline data collection, and methods for addressing them:

\section{Unplanned events and unexpected delays}

- There was an unplanned delay between the completion of the household listing and the start of the adolescent survey as the anthropometric equipment was held in customs until the appropriate duty free clearances could be obtained. This delayed the start of the adolescent interviews and increased the time between the household listing and adolescent survey. Project personnel worked on almost a daily basis with the appropriate personnel at DFID and customs clearing agents to process the appropriate paperwork in as timely a manner as possible.

- The Council purchased three Toyota Landcruiser Hardtops to carry field teams. The vehicles are durable for traveling on dirt roads and rough terrain. Despite purchasing these vehicles months in advance, it took a very long time to complete the bidding process, confirm purchase and payments, excute delivery, obtain clearance from customs and insure and register the vehicles. The fieldwork vehicles only arrived after fieldwork commenced in rural areas and the project relied on smaller $4 \times 4$ vehicles. Moving forward, follow-up fieldwork activities will benefit from having these heavier duty vehicles available.

- To proceed with the testing of HSV-2 samples, a validation of the laboratory testing protocols must be completed by an external laboratory. To complete the validation, known samples of HSV-2 must be provided. Unfortunately, laboratories in Zambia do not have HSV-2 samples with known status readily available that are authorized for such use and specimens from outside the country were required. A Materials Transfer Agreement with the Ministry of Health needed to be approved to import the specimens from South Africa. The approval from Minstry took considerably longer than expected. Hence, laboratory testing of HSV-2 specimen and results dissemination started significantly behind schedule. We have adjusted by asking the laboratory to increase its weekly testing rate and have followed with dissemination activities at each site as soon as results are available. 


\section{Fieldwork Implementation}

- Given the size of the fieldwork teams for the household listing and adolescent survey, the distances covered and the number of days of fieldwork, there were a large number of the logistical, administrative and financial challenges that had to be addressed by project coordinators and office backstopping staff involved in the study: adequate and safe transportation, staff temporary housing, and processing large amounts of funding stand out. This effort required coordination among the fieldteam and office staff who, at times, had competing needs and timelines. Appropriate office staffing need be employed, improved training of fieldstaff on office procedures and appropriate tools for financial reporting used. Expectations and process limitations need to be noted up front, particularly as it pertains to release of study funds. Further, relationships need be carefully managed throughout the fieldwork period.

- Three very large teams, specifically, the household survey team, the adolescent survey team and the AGEP programme team had to effectively communicate to meet common goals and timelines, even when they had their own team objectives and tasks to complete. The teams were not always dynamic in addressing priorities of other teams when responsibilities overlapped, where procedures were not previously well defined and roles not clearly delineated. This issue was particularly pertainent to sensitizing community members, local leaders and health facility personnel. Defining team level responsibilities and procedures prior to fieldwork, documenting communications channels and having regular team leader conference calls to address issues would improve the effectiveness of teams meaning overall project goals.

- As a result of community beliefs about specimen collection and the use of computer based data capture tools, some community members perceived the AGEP survey team as Satanists. Thus, some parents and adolescents declined to participate in the survey, whereas others accepted to participate but refused to test for HIV and/or HSV2. Despite each team's responsibility for community engagement, consistent engagement and sensitization was less than what was needed. The project fieldwork coordinator and biomarker coordinator were able to successfully overcome most resistence by directly engaging households, community and religious leaders to address these issues, but these visits increased their work burdens. Community sensitization requires early intiation and consistent and repeated interaction.

- Due to lower than expected interviews completed per day by female enumerators, data collection took longer than planned. Bicycles had been procured to faciliate the reaching of households and, while highly effective when used by the male enumerators in the household listing, the female interviews had difficulty using the bicycles consistently due to a lack of ability or the rough terrain. The lower daily rates of data collection increased fieldwork costs and extended data collection into the rainy season, the latter making it difficult to reach communities and adolescents. The length of the interview process needs to be adjusted or a larger fieldstaff recruited to complete fieldwork in a shorter time frame to avoid the rainy season. Alternative transport for the female staff, e.g., chauffered motorcycles should be assessed within a benefits/risk perspective. Having the project Toyota Landcruisers immediately available for fieldwork will be a benefit to fieldwork implementation in rural areas. 


\section{Data Quality}

- Misreporting of information by the household head and miscoding of information by the interviewer affects both fieldwork effort and the quality of data. While we can correct information for those observed at the time of the survey, those who did not fit the eligibility criteria due misreporting and miscoding were not observed. For the most part, however, these errors should be random.

- The age distribution group differs between the household listing and the adolescent survey, with a greater proportion of girls in the adolescent survey observed in the younger age groups. The greater observation among younger adolesents is believed to be partially a function of the fact that some interviewers may have misreported ages at survey to avoid completing additional components of the study, specifically the anthropometric and biological specimen collection. Suspect ages can be assessed and corrected in subsequent rounds of data, but the missing baseline data cannot be obtained.

- The electronic data capture hardware technology and software programme developed at the Council, although used in previous studies, are relatively new. While performing exceptionally, the programme is limited in the ability to easily view and export the data. This limited our ability to do real time quality assurance checks on the electronic data. As a result a small number of recorded completed interviews were lacking electronic data. Additionally, the programme is limited in allowing the interviewer to make changes due to misreporting by the respondent; being able to go back only two previous questions. This led to an unwieldy and fallible process of documenting errors on paper or restarting the interview. We will work with the Council's technology department to allow easier monitoring and more timely export, as well as a greater ability for enumerators to backtrack along the survey.

- The HSV-2 blood specimens were collected by finger-prick. While this method is adequate if a large enough sample is obtained, if an insufficient amount of whole blood is obtained, the specimen cannot be used for testing. Obtaining insufficient samples occurred more often early in the survey as enumerators had limited experience or practice in collecting blood and retraining was often required. Collecting whole blood through venipuncture is an alternative; however, it requires that trained nurses rather than trained enumerators travel with the team, significantly increasing costs. While the HSV-2 testing is still underway, we are confident from similar approaches used in a Population Council study in Malawi that the increased monitoring and quality assurance checks in the field is more cost-effective for obtaining the HSV-2 status of participants. 


\section{Research Timeline}

A summary of AGEP research data collection activities can be viewed in Table 13 below. Activities include pretesting instruments and procedures, a household mapping and listing to develop a sampling frame for AGEP's programme and research. The baseline adolescent survey took place in 2013 and early 2014 prior to programme implementation at the sites. Annual observation of adolescents will be conducted through mid-2017, with a final sample aged 1423. Repeated observation of adolescents on an annual basis will minimize our attrition rates, provide more valid measures of the timing of transitions and add power to the statistical analysis of study outcomes. Qualitative interviewing, including semi-structured interviews and focus group discussions will take place at baseline, Round 3 (at end of programme) and Round 5 (2-years post programme). At baseline, HIV and HSV-2 testing were conducted among adolescents 15-19. At the end of the programme period (Round 3 ) and in the final round of data collection (Round 5) HIV and HSV-2 status will again be obtained.

Table 13. AGEP research data collection activities and schedule

\begin{tabular}{cccll}
\hline Round & Year & Ages & Data collection & Programme \\
\hline 1 & 2013 & $10-19$ & Pretesting Instruments and Procedures & \\
1 & 2013 & - & Household listing & AGEP Begins \\
1 & $2013-2014$ & $10-19$ & Adolescent Survey; Qualitative; HIV, HSV-2 (15-19) & 1st Full Year \\
2 & 2014 & $11-20$ & Adolescent Survey & 2nd Full Year \\
3 & 2015 & $12-21$ & Adolescent Survey, Qualitative; HIV, HSV-2 (15-21) & 1 Year Post \\
4 & 2016 & $13-22$ & Adolescent Survey & 2 Years Post \\
\hline
\end{tabular}

\section{POPULATION} COUNCIL

Ideas. Evidence. Impact. 